Building Services Engineering

Research and Technology

\title{
Design Summer Year weather - outdoor warmth ranking metrics and their numerical verification
}

\begin{tabular}{|c|c|}
\hline Journal: & Building Services Engineering Research and Technology \\
\hline Manuscript ID & BSE-C-15-087.R2 \\
\hline Manuscript Type: & Original Manuscript \\
\hline Date Submitted by the Author: & $\mathrm{n} / \mathrm{a}$ \\
\hline Complete List of Authors: & $\begin{array}{l}\text { Ji, Yingchun; Salford university, Department of the built environment } \\
\text { Zhang, Yi; Energy Simulation Solutions Ltd, LE2 7DA } \\
\text { Korolija, Ivan; De Montfort University, IESD } \\
\text { Futcher, Julie; Urban Generation }\end{array}$ \\
\hline Keywords: & $\begin{array}{l}\text { Design Summer Year, Test Reference Year, Weather Data, EnergyPlus, } \\
\text { Overheating }\end{array}$ \\
\hline Abstract: & $\begin{array}{l}\text { The existing methods of selecting Design Summer Year weather data rely } \\
\text { on the outdoor dry bulb temperature (DBT) without considering solar } \\
\text { radiation and wind which can impact on indoor thermal conditions. This } \\
\text { research sets out to examine the existing outdoor warmth ranking metrics } \\
\text { and proposes a new warmth ranking metric (solar air temperature) which } \\
\text { takes into account not only DBT but also solar and wind conditions. } \\
\text { Parametric study was carried out using } 5 \text { typical UK dwelling models, by } \\
\text { varying parameters associated with building design and operation, a large } \\
\text { model population were generated to statistically determine how well the } \\
\text { outdoor warmth ranking metrics correlate the predicted indoor warmth. } \\
\text { The outdoor warmth ranking was made for the } 20 \text { years source weather } \\
\text { data (1976-1995) in London and both CIBSE single temperature criterion } \\
\text { and BS EN } 15251 \text { adaptive criteria were used to judge overheating in } \\
\text { buildings. It is found that the predicted indoor warmth are mostly arbitrary } \\
\text { in nature and none of the existing and newly proposed outdoor warmth } \\
\text { ranking metrics can strictly correlate. The research also discovers the } \\
\text { significant differences between the predicted overheating occurrence and } \\
\text { severity in the warmth ranking of weather years. }\end{array}$ \\
\hline
\end{tabular}

\section{SCHOLARONE \\ Manuscripts}




\title{
Design Summer Year (DSY) weather - outdoor warmth ranking metrics and their numerical verification
}

\author{
Yingchun Ji ${ }^{1}$, Yi Zhang ${ }^{2}$, Ivan Korolija ${ }^{3}$ and Julie Futcher ${ }^{4}$ \\ ${ }^{1}$ School of the Built Environment, University of Salford, Salford, M5 4WT \\ ${ }^{2}$ Energy Simulation Solutions Ltd, LE2 7DA \\ ${ }^{3}$ IESD, De Montfort University, Leicester, LE2 7DA \\ ${ }^{4}$ Urban Generation
}

Telephone: 00441612954841 / Email: y.ji@salford.ac.uk

\begin{abstract}
:
The existing methods of selecting Design Summer Year weather data rely on the outdoor dry bulb temperature (DBT) without considering solar radiation and wind which can impact on indoor thermal conditions. This research sets out to examine the existing outdoor warmth ranking metrics and proposes a new warmth ranking metric (solar air temperature) which takes into account not only DBT but also solar and wind conditions. Parametric study was carried out using 5 typical UK dwelling models, by varying parameters associated with building design and operation, a large model population were generated to statistically determine how well the outdoor warmth ranking metrics correlate the predicted indoor warmth. The outdoor warmth ranking was made for the 20 years source weather data (1976-1995) in London and both CIBSE single temperature criterion and BS EN 15251 adaptive criteria were used to judge overheating in buildings. It is found that the predicted indoor warmth are mostly arbitrary in nature and none of the existing and newly proposed outdoor warmth ranking metrics can strictly correlate. The research also discovers the significant differences between the predicted overheating occurrence and severity in the warmth ranking of weather years.
\end{abstract}

Keywords:

Design Summer Year, Test Reference Year, Weather Data; EnergyPlus; Overheating.

\section{Introduction}

The importance of using dynamic thermal modelling to predict the likely thermal performance of a building at the design stage has been widely recognized by the building industry by assisting design optimisation, demonstrating building code compliance and improving risk (i.e. overheating) based decision-making. This approach allows easy comparison of the thermal performance of buildings under various conditions whilst using standardised weather data.

In the UK the current standard weather data for dynamic thermal modelling are the Test Reference Year (TRY) and the Design Summer Year (DSY) weather data sets. ${ }^{1}$ The 
Charted Institution of Building Services Engineers (CIBSE) periodically releases new weather data for 14 UK cities, the latest release for all 14 locations was 2005 . TRY weather year is the statistical average of historical measured weather, and is considered to represent average weather conditions. ${ }^{2}$ The weather year is derived by selecting the most representative individual months and combining the chosen 12 months, typically taken over a 20 year period. Unlike TRY which is often used to assess building energy performances, DSY is defined as a 'near extreme' weather year over a period of time, typically 1 in 8 years, and is commonly used to assess potential overheating risks in free running buildings. As discussed in CIBSE Guide $\mathbf{J}(2002)^{2}$, the selection procedures of DSY are: a) calculate the yearly average dry-bulb temperature (DBT) from April to September for a period of 20 years; b) using averaged DBT to rank the 20 years; $c$ ) select the mid-year of the upper quartile as the sample year, namely, the 'near extreme' DSY weather data (year 1989 was selected as DSY using this approach). Whilst this method has the merit of simplicity, it has known shortcomings. For free running buildings (i.e. naturally ventilated), dwellings and/or non-domestic premises, other weather parameters, such as intensity of solar radiation (direct and diffuse), cloud cover, as well as wind strength and direction, also impact on indoor thermal response. Therefore merely using DBT statistics to represent outdoor warmth may not be adequate.

The problems with the DSY definition from CIBSE Guide $\mathrm{J}$ have been widely reviewed in recent years. It was reported that the level of indoor warmth of naturally ventilated buildings has been predicted to be lower for DSY than TRY. In other words buildings modelled using TRY weather data are shown to have higher indoor air temperatures for some locations among the 14 locations in the UK. ${ }^{3,4,5}$ This is clearly a theoretical contradiction between the definitions of DSY and TRY as one naturally would expect that the 'near extreme - DSY' weather to be warmer than the 'average weather - TRY' for any given site. This 'contradictive' judgement (TRY is warmer than DSY) was based on the predicted indoor warmth, often referred to as the number of hours over a threshold temperature, i.e. $28^{\circ} \mathrm{C}$ from CIBSE Guide $\mathrm{A}^{1+}$ In addition, both DSY and TRY are currently defined using historical weather data, their definitions based on the outdoor warmth, irrelevant to buildings themselves. The 'argument' here being as the form a buildings also plays an important role on indoor environment. The likely thermal responses of different forms of a building against one particular weather condition will be naturally different, which is why the primary purpose of modelling tools is to perform various design optimizations.

The underlying problem of DSY lies not only with its definition, but that of the expectation of a building's thermal response. That is, it is reasonable to assume that indoor warmth should correlate the outdoor warmth. and that when a building model is simulated for each of the 20 year source weather data, ideally the 'indoor warmth' should reflect the exact sequence of the outdoor warmth, or at least, the chosen DSY should produce a warmer indoor condition compared to the corresponding TRY. This has proved not the case for a number of sites in the UK by Jentsch et al (2014) where the fundamental limitations of the DSY were discussed. ${ }^{6}$ Jentsch's research identified 4 key problems in terms of DBT averaging, DBT distribution, solar radiation, and missing data. These underlying problems have wider implications on the prediction of likely 
building thermal performances and it is unlikely for the current chosen DSYs weather to always support the 'expected' consistency with the corresponding TRYs.

\section{Watkins et al proposed a new approach in selecting near extreme weather using UKCP09 projections. ${ }^{7}$ This approach relies on large amount of projected weather data to make the statistics reliable. When working with historical weather data in selecting DSY, this new approach is not suitable as the historical weather data are limited (20 years for this work). On recognition of the problem-CIBSE also commissioned research} to examine alternative methods of selection of DSYs since $2009{ }^{4}$ which led to the very recent publication of CIBSE TM49 - "Design Summer Years for London". ${ }^{6}$ This technical manual (TM), which focuses on London, investigated a new selection metric "weighted cooling degree hours (WCDH)" to judge the outdoor warmth. WCDH is based on adaptive comfort temperature and it is closely related to the likelihood of thermal discomfort, able to eliminate the problems associated with DBT averaging and distribution to certain extend, however, it is a DBT only metric without considering impacts of overheating in buildings from other weather parameters such as solar radiation and wind condition.

The selection method of DSYs from CIBSE TM49 has yet to be explored in practice. However there are two main uncertainties that this method does not address: the likely impacts on discomfort from weather parameters other than DBT; and the potential thermal responses of various built forms, i.e. how well the outdoor warmth defined by WCDH correlates the predicted indoor warmth in various building forms. In this research, these two uncertainties will be investigated by proposing a parameter of solar air (Sol-air, see section 3.3) temperature, which can take into account the effects of DBT, solar radiation and wind speed; and using various building forms the role of building on the indoor thermal responses will be explored aiming to statistically verify the various ranking methods, including the WCDH.

\section{Chosen source weather data}

In the UK, standardized weather data such as TRYs and DSYs were proposed by CIBSE in late 1990s to represent 'typical' and 'near extreme' weather conditions. These weather files were later used substantially for detailed building performance analysis by both academics and industry professionals. The first release of these standardized weather files was in year 2002 for three UK locations: Edinburgh, Manchester and London, through the publication of CIBSE Guide J (2002). ${ }^{2}$ The 20 year source weather data was from the period 1976 to 1995, in which only London had the complete set the 20 years data, whilst Edinburgh and Manchester have 17 and 13 complete sets of data respectively. These raw data sets were prepared from direct observation at various Met Offices weather stations, i.e. for London weather data, the synoptic data was obtained from Heathrow and the radiation data from Bracknell.

British Atmospheric Data Centre (BADC) database holds all the raw weather data across the nation, this data can be downloaded for research purpose upon applications to the BADC. These measured/observed weather data are not as neat as expected, for 
example, for some years missing and unreliable data are evident. These gaps were

handled by some appropriate smoothing and interpolation algorithms. ${ }^{2,4}$

Formatted: Endno

The current widely used CIBSE standardized weather data was those released in the year of 2005 where the source weather years were from 1983 to 2004 for London (22 years, year 1989 was selected as DSY again). This release has a greater geographical coverage (14 UK sites). Due to fewer sites where radiation data were measured and these sites were also closing in recent years, majority of the radiation data from those source weather years were calculated from measured cloud cover data using mathematical models, and the a sanitizer programme was used to smooth the data between adjacent months of TRYs. ${ }^{8}$

For this research, the source weather years of London from 1976-1995 are used as they are more robust in terms of radiation data (largely through observation rather than calculation). For the 14 UK sites with hourly weather data, London (Heathrow) DSY data are the most often used for overheating evaluation, and its DSY year is broadly consistent with its TRY. It is intentionally not choosing those problematic sites (DSYs and TRYs are not consistent, such as Newcastle, Nottingham or Manchester) discussed by Jentsch et al. ${ }^{6}$ The other reason for not using these was the number of complete | source weathers are significantly less than 20 years. $\underline{87}$

The key weather parameters within the source weather years include: global solar irradiation (gsr), diffuse solar irradiation (dsr), cloud cover (cc), dry-bulb temperature ${ }^{\circ} \mathrm{C}(\mathrm{dbt})$, wet-bulb temperature ${ }^{\circ} \mathrm{C}(\mathrm{wbt})$, atmospheric pressure (atpr) and wind speed (ws). These parameters will be directly used to determine the outdoor warmth using the proposed sol-air definition discussed in section 3.3.

\section{Outdoor warmth ranking metrics of source weathers}

\subsection{Number of hours over fixed temperatures}

Using the 'number of hours over a fixed temperature' from April to September to rank the source weather years is consistent with the single temperature overheating criterion from CIBSE Guide A. This metric indicates the amount of 'high' temperatures that correlate directly with the indoor overheating for free running buildings. ${ }^{3}$ The downside of this method is the uncertainty of what temperature is to be used to examine the 'number of hours over' as it may vary due to various building characteristics including variations in built forms, internal gains and occupation patterns. For example, a lower outdoor temperature may cause indoor overheating for a high heat gain building model, while the same building model with low internal heat gains, overheating may not happen at that temperature. Therefore it would make more sense to evaluate a range of temperature rather than a particular fixed one.

The number of hours over $(\mathrm{HO})$ a fixed temperature range between $22^{\circ} \mathrm{C}$ to $28^{\circ} \mathrm{C}$ was calculated for the 20 source weather years as shown in Table 1 (the 20 years ranking order is illustrated in table 4). The accumulated degree hours (ADH) were also counted. The ADH is the sum of the 'degree hours $(d \cdot h)$ ' over the relevant threshold temperature. 
For example, using $26^{\circ} \mathrm{C}$ as a threshold temperature, a temperature at $26.2^{\circ} \mathrm{C}$ has $0.2 \mathrm{~d} \cdot \mathrm{h}$; a temperature at $28.3^{\circ} \mathrm{C}$ gives $2.3 \mathrm{~d} \cdot \mathrm{h}$. ADH is the sum of all these degree hours. It is a metric to indicate the severity of warmth rather than occurrence. ${ }^{9}$

Insert Table 1 here

\subsection{Weighted cooling degree hours (WCDH)}

The WCDH is based on adaptive comfort temperature which is calculated by the running mean $\left(\mathrm{T}_{\mathrm{rm}}\right)$ of the outdoor $\mathrm{DBT}, \underline{\mathbf{3 3}, \mathbf{5} 5}$ and it is the preferred metrics to judge outdoor warmth by CIBSE TM49. ${ }^{10}$ The expression of WCDH is below ( $N$ is the total number of hours from April to September inclusive: 4392):

$W C D H=\sum_{i=1}^{N}\left(T_{d b t}^{i}-T_{\text {comf }}^{i}\right)^{2} \mid T_{d b t}^{i}>T_{\text {comf }}^{i} \quad$ Eq. 01

where $\boldsymbol{T}_{\text {comf }}$ is the limiting comfort temperature defined by BS EN $15251^{[11]}$ :

$$
T_{\text {comf }}=0.33 \operatorname{Max}\left(10, T_{r m}\right)+18.8, \text { where } \quad \text { Eq. } 02
$$

$T_{r m}=\alpha T_{r m-1}+(1-\alpha) T_{d m-1} \quad$ Eq. 03

$\left(\mathrm{T}_{\mathrm{rm}-1}\right.$ and $\mathrm{T}_{\mathrm{dm}-1}$ are the running mean and daily mean temperature previous day)

$\mathrm{T}_{\text {comf }}$ is used as a referencing temperature to calculate WCDH in order to judge outdoor warmth for a particular weather. As discussed in TM49, $\stackrel{109}{ }$ the quadratic nature of WCDH is broadly consistent with the relationship between fraction of people uncomfortable and the departure from the comfort temperature. Table 2 below shows the calculated weighted cooling degree hours $(\mathrm{WCDH})$ over comfort temperature $\mathrm{T}_{\text {comf }}$, and the accumulated degree hours over $\mathrm{T}_{\text {comf }}(\mathrm{ADHC})$ for the 20 years source weather years. Here the ADHC is defined the same as ADH (section 3.1) but the limiting temperature is $\mathrm{T}_{\text {comf }}$ rather than a fixed temperature. Figure 1 shows the relationship between source weather data, daily mean, running mean and the $\mathrm{T}_{\text {comf }}$ for the year of 1976.

Insert Table 2 here

Figure 1 London Heathrow 1976 DBT data (April to September only):

\subsection{Sol-air temperature}

Solar-air temperature (often referred as 'solair' or 'sol-air' temperature) is an artificial temperature which represents the combined climate variables on a surface in question, i.e. short wave irradiation, long wave radiation exchange, air temperature and wind speed. ${ }^{12}$ A simple empirical expression for sol-air temperature $\left(t_{s a}\right)$ is defined by Thakur 1989. 
The parameters in the above equation is defined on a sunlit surface: $t_{a}$ is the atmospheric temperature (ambient dry bulb temperature), $\alpha_{s}$ is the absorptivity, $I_{g}$ is global irradiation, $h$ is combined heat transfer coefficient (convective and radiative), $\varepsilon$ is long-wave surface emissivity, and $\Delta R$ is the net difference between the long-wave incident radiation from the SKY and surroundings and the radiation emitted by a black body at $t_{a}$. In practice, $\Delta R$ is assumed to be zero $\left(0 \mathrm{~W} / \mathrm{m}^{2}\right)$ for a vertical surfaces and $63 \mathrm{~W} / \mathrm{m}^{2}$ for horizontal surfaces, and $h$ is taken $17.0 \mathrm{~W} / \mathrm{m}^{2} \mathrm{~K} .{ }^{14,15} \mathrm{In}$ CIBSE Guide J, $\alpha_{\mathrm{s}}=$ 0.9 is used for dark coloured surfaces (or 0.5 for light coloured surface); long-wave surface emissivity $\varepsilon$ is assumed to be $0.9 .^{2}$ Therefore, using Eq. (04) sol-air temperature can be obtained when air temperature and global irradiation are known.

Eq. (04) is an empirical solution to calculate sol-air temperature, and is straightforward to use. However, it ignores the variations of sky long-wave irradiance and wind speed related heat transfer coefficient. A quartic equation was derived for a horizontal plane to calculate its absolute surface temperature $T_{s}(\mathrm{~K})(\mathrm{Eq} .05$, see Appendix A for detailed derivation and how the relevant parameters are defined).

$\varepsilon \sigma T_{s}^{4}+h_{c} T_{s}-\left(\alpha_{s} I_{g}+\varepsilon R_{s k y}+h_{c} T_{a}\right)=0$

Eq. 05

where, $\alpha_{s}, I_{g}$ and $\varepsilon$ are defined as Eq. (04), $\sigma$ is the Sefan-Boltzmann constant $\left(5.6697 \times 10^{-8}\right), R_{s k y}$ is the daytime sky long-wave irradiance from the atmosphere falling on a horizontal surface, $h_{c}$ is the convective heat transfer coefficient $\left(\mathrm{W} / \mathrm{m}^{2} \mathrm{~K}\right)$, and $), T_{a}$ is the absolute atmospheric temperature $(\mathrm{K})$. The resulting sol-air temperature $t_{s a}^{\prime}$ is defined as:

$t_{s a}^{\prime}=T_{s}-273.15$

Eq. 06

Sol-air temperatures calculated by Eq. (04) and (06) are shown in Figure 2. This simple empirical expression always gives a higher sol-air temperature than its corresponding $t_{a}$ by definition. However, the sol-air temperature can go well below the dry bulb temperature $t_{a}$ when using Eq. (06). The difference is clearly noticeable in Figure 2, and also shown by the April to September (inclusive) averaged sol-air temperature (Table 3).

Figure 2 Ambient dry bulb temperature $t_{a}$ vs sol-air temperatures calculated by Eq. $04 \&$ 06.

Insert Table 3 here

\subsection{Warmth ranking}

The warmth ranking order (top to bottom represents cooler to warmer) using the metrics discussed earlier (data from Table 1, $2 \& 3$ ) and is summarised in Table 4. 'Avg. DBT' is the averaged DBT from April to September - the sole ranking metric for choosing DSY before TM49 was released. For the chosen DSY (L89 - London 1989), the number of hours over fixed temperatures is broadly consistent as it appears in the third warmest 
position often, however, it does vary from second to fifth place. L89 tends to shift towards fifth place whilst the limiting fixed temperature is higher. The metrics of WCDH and the accumulated degree hours over comfort temperature limit ranked L89 in fourth place. If the rule of 'midyear of the upper quartile' is used, ${ }^{2,3,5}$ the year 1990 (L90) should be chosen as the DSY. For April to September averaged sol-air temperature calculated by Eq. (04) \& (06), L89 is ranked the second. Overall, the years of 76, 95, 89, $90 \& 83$ are the top warmest years among the 20 years. The year 1976 was consistently warmest. Unlike other DBT only metrics, the sol-air temperature also takes into account the impacts from solar radiation and wind speed. As a referencing metric for this research, sol-air temperature was only calculated on a horizontal surface (i.e. a flat roof) where strong influences from solar radiation and wind speed would naturally exist. The very last column is the sol-air temperature calculated using Eq. (06) but its wind related convective heat transfer coefficient $h_{c}$ is fixed as $17 \mathrm{~W} / \mathrm{m}^{2} \mathrm{~K}$ (ref table 3). This allows a cross comparison between the two methods of Eq. (04) and (06) when wind condition is the same (columns $t_{\mathrm{sa}}$ and ${ }^{*} \mathrm{t}_{\mathrm{sa}}$ ). The ranking orders between the two are broadly the same for the warmest 5 years (also consistent with other DBT only metrics). It is worth noting that statistically the 'averaged April to September sol-air temperature' will bear the same averaging and distribution problem as discussed by Jentsch et al, ${ }^{6}$ further consideration of appropriate ranking method for sol-air temperature may be necessary, i.e. number of hours over a fixed sol-air temperature, using the concept of weighted cooling degree hours, or statistical method such as Finkelstein-Schafer (FS) statistic to compare cumulative distribution functions (CDFs) of sol-air temperature. ${ }^{16}$

How to use these metrics to assess outdoor warmth determined by the sol-air temperature will be investigated separately. Here the averaged sol-air temperature was used for simplicity and consistency with the method used by CIBSE Guide J 2002. The TRY in the ranking here is for reference only. The numerical verification procedure (discussed in the following section) will be performed against the ranking order in Table 4.

Insert Table 4 here

\section{Numerical verification}

\subsection{Building models}

To facilitate the numerical verification of the research proposed here, five modern domestic house models are used (Figure 3). These houses originated from Urban Area (2012) ${ }^{17}$ and their detailed descriptions can be found in Korolija \& Zhang (2013). ${ }^{18}$ The selection of these five house types provides a good mix of sizes, forms and fenestration arrangements as well as a good coverage of new dwellings across the UK. Type $1 \& 2$ are two detached hours, type 3 is two semi-detached houses, and type $4 \& 5$ are two terraced houses

Figure 3 The five house types for numerical verification 
Building dynamic thermal models of these house types were created in EnergyPlus and parameterized using jEPlus, so that they can represent various designs and constructions of dwellings in the UK. jEplus is a third party parametric study toolkit developed for EnergyPlus. ${ }^{19}$ Table 5 gives a summary of all parameters (and their possible variations) considered in this study. The total number of possible variations (simulation models) is in the order of $3.3 \times 10^{11}$. Note that each simulation model needs to be executed with each of the weather years of London from 1976 to 1995, the total number of simulation cases would aggregate to over $6.6 \times 10^{12}$, which is impossible to achieve if the full parametric results are required.

\section{Insert Table 5 here}

Instead of a full parametric study, a random sample is taken to represent the distribution of the building characteristics of the dwellings. The Latin Hypercube Sampling (LHS) method is used to create the random sample. A ratio of 10 between the size of the random sample and the number of variables (16 in this case) is often quoted as "large enough" in literature. ${ }^{20}$ So in this case, the sample size of 200 is chosen. The LHS sample of building models are then used to evaluate the likelihood of outdoor warmth causing indoor overheating with different weather years. In total, 4000 simulations are carried out. Results are given in Section 5. Further numerical verifications were also performed by using a sample size of $400 \& 800$ random models. Larger samples do not alter the result set presented in Section 5 which reassures that the original sample size is sufficient to represent the total module population.

\subsection{Overheating criteria}

The numerical verification of the discussed outdoor warmth ranking order is performed using the building models discussed in section 4.1. A set of criteria for assessing indoor warmth and overheating risk related to the weather years are discussed below.

The single overheating criterion from CIBSE Guide $\mathrm{A}_{\mathbf{A}}^{\mathbf{1 1}}$ has long been used to assess overheating in free running buildings. ${ }^{21,22,23 \& 24}$ This criterion is used to assess number of hours the indoor operative temperature over $28^{\circ} \mathrm{C}$, i.e. for offices, overheating is judged if there is more than $1 \%$ occupied hours when operative temperature is over $28^{\circ} \mathrm{C}$. For dwellings, the limiting temperature for living rooms is $28^{\circ} \mathrm{C}$ but for bedrooms, where adaptive measures are limited during sleep, $26^{\circ} \mathrm{C}$ is used.

Adaptive overheating criteria from BS EN $15251 \stackrel{\mathbf{1 1 0}}{\mathbf{1}}$ is also used in this research. Extensive field studies ${ }^{25}$ found that the indoor acceptable thermal conditions are related to the outdoor environment. This method was also discussed in CIBSE Guide A, arguing that "people in daily life are active in relation to their environment, given time and opportunity, they can make themselves comfortable by adjusting their clothing, activities and their thermal environment'. The comfort temperature is therefore defined as a band (rather than a single threshold) for free-running buildings, which applies to majority of the dwellings in the UK in summer time. BS EN 15251 defines three categories: Category I - the most stringent one when there are "High level of expectation and is recommended for spaces occupied by very sensitive and fragile persons with special requirements like handicapped, sick, very young children and elderly persons"; Category II is for "Normal level of expectation and should be used for 
new buildings and renovations"; and Category III is for "An acceptable, moderate level of expectation and may be used for existing buildings". The upper limit temperatures for these categories are $2^{\circ} \mathrm{C}, 3^{\circ} \mathrm{C}$ and $4^{\circ} \mathrm{C}$, respectively, above the comfort temperature calculated using Eq. (02) (see $\mathrm{T}_{\text {comf }}$ in Figure 1).

The number of hours indoor temperature exceeds either the fixed threshold temperatures of $26^{\circ} \mathrm{C}$ (bedrooms) and $28^{\circ} \mathrm{C}$ (living rooms) or the adaptive comfort upper limits shows only occurrences of overheating but not its severity. CIBSE TM52 provides three criteria to judge overheating which includes both overheating occurrence and severity, as well as the maximum allowed indoor operative temperature. ${ }^{26}$ However, it is difficult to use all three criteria to rank the indoor warmth when different weather years are used. Therefore due to the nature of this research, only the overheating occurrence and the accumulated degree hours are counted and used to make the ranking order, based on the predicted indoor operative temperature.

The list of metrics for assessing indoor warmth is summarized below (Table 6). Please note that separate metrics are used for "living room" and "bedroom" spaces, respectively, as their occupancy patterns and overheating temperature thresholds are different.

Insert Table 6 here

\subsection{Statistic voting of indoor warmth}

The following procedure was used to assess the predicted indoor warmth and to rank the 20 years historical weather data by the occurrence of overheating hours and the accumulated overheating degree hours.

- A random sample of 200 simulation cases are generated from the parametric building models use LHS method provided in jEPlus

- The 200 simulation cases are executed with each of the 20 London weather years (1976-1995)

- From the results of each simulation case, the 20 weather years are ranked for indoor warmth in the dwelling by each of the metrics in Table 6.

- The ranking of the weather years, according to each metric, are collected from the 200 simulation cases. For each weather year, the frequency of ranks are calculated and plotted on a histogram chart.

- For each individual weather data source, its highest probability ranking will be used to determine its final ranking order. This predicated indoor warmth ranking order will be examined against the outdoor warmth ranking order in table 4 . 


\section{Results and discussions}

Figures 4 to 11 show the ranking probabilities for individual weather years using different indoor overheating measures: CIBSE Guide A single overheating criterion, BS EN 15251 Adaptive category limits (I, II, III), and their accumulated degrees hours. All these plots are against the Living rooms where the adaptive approach can apply. For Bedrooms where occupants sleep, there are less opportunities to apply the adaptive | approach. $1 \mathbf{1 1 0}$ Results for Bedrooms in table 6 were plotted but are not discussed in this paper as they showed similar patterns as the Living rooms. The ranking probability can be interpreted as the percentage likelihood of appearance on a particular ranking position among all possible sample cases simulated for a particular weather year, for example, in Fig 4, there is $32 \%$ chance the year 1995 weather is the warmest ( $1^{\text {st }}$ position); while for the year of 1994 , the chance of being in the $6^{\text {th }}$ warmest position is $86 \%$. These predicted ranking probabilities (figures 4 to 11) clearly show the arbitrary nature of the predicted indoor warmth under various criteria, i.e. no single weather year can hold one particular ranking position for the sampled simulations.

\subsection{Overheating occurrence}

For indoor warmth prediction using the CIBSE single overheating criterion of 'number of hours over $28^{\circ} \mathrm{C}$ ', Figure 4 shows that 1976 has the highest probability, a $57 \%$ chance of being the warmest year and therefore takes $1^{\text {st }}$ position on graph, whilst 1995 has a $32 \%$ chance of being the warmest, and 1989 has a $11 \%$ chance. The likelihood of appearing in the second warmest year ( $2^{\text {nd }}$ position on the graph), falls to 1995 which has a $50 \%$ chance, and the third warmest position ( $3^{\text {rd }}$ position on the graph) is 1989 with a $53 \%$ chance

Fig 4 C1 - Ranking probability by the number of hours over 28C for Living rooms while occupied (x-axis is ranking position and $y$-axis is the probability of being that position for a particular year, same hereafter)

One obvious observation is that none of the ranking orders defined in table 4 can be guaranteed due to the fact that the predicted the indoor warmth is individual cases subjective, i.e. for the year of $1976,57 \%$ of the sample cases it is the warmest, whilst the rest of the sample cases it is not the warmest. This means that the warmth defined by using the outdoor climate condition does not always correlated with the predicted indoor warmth. However, considering the highest probabilities of being the top 3 warmest (years 1976, 1995 \& 1989), results shown in Figure 4 are broadly consistent with majority of the ranking orders shown in table 4.

When using the 'adaptive approach' i.e. number of hours over adaptive comfort temperature (Category I upper limit, Figure 5), 1976 has an 85\% probability of being the warmest year, whilst 1989 has more chances of being the warmest $(22 \%)$ than the year $1995(3 \%)$. It is also worth noting that the possibilities of 1995 and 1989 remaining in the second and the third warmest positions for are still the most probable although the percentages $47 \%$ and $38 \%$ respectively are no longer as high. 
The same can be said for the results shown in Figures $6 \& 7$, where similar probabilities for 1976 (warmest) and 1995 (second warmest) exist, although in this instance whilst 1989 , holds the highest probability to retain $3^{\text {rd }}$ position the probability has dropped below $40 \%$.

Fig 5 C10 - Ranking probability by the number of hours over BS EN 15251 adaptive Category I for Living rooms

Fig 6 C12 Ranking probability by the number of hours over BS EN 15251 adaptive Category II for Living rooms

Fig 7 C14 Ranking probability by the number of hours over BS EN 15251 adaptive Category III for Living rooms

There are noticeable differences between CIBSE Guide A criterion and the adaptive approach from BS EN 15251. For all the three categories (Figures 5 to 7), it is clear that the 1976 holds its warmest position better than the single temperature criterion (Figure 4). However, for the other warm years, for example 1983, 1990, 1989 and 1995, this is less obvious. As shown in Figure 4, the year 1994 was relatively stable among the 20 years with an $86 \%$ probability for being the $6^{\text {th }}$ warmest, higher than any other sample years. 1984 ranks next to 1994 and relatively holds its $7^{\text {th }}$ position well in Figure 4. Whilst in Figures 5 to 7, these two years 1994 and 1984 also generally hold their positions well. The observation of other years varies in their positions in terms of indoor warmth, which are largely scattered, however, 1978 and 1988 are consistently the least warm years among the 20 sample years.

\subsection{Overheating severity}

Ranking probabilities by counting the accumulated degree hours over $28^{\circ} \mathrm{C}$ show that 1976 is no doubt the warmest year without exception (Figure 8) and the year 1995 holds its second warmest position well with a $95 \%$ probability. However, under this criterion, the highest probability for the year 1989 is just over $50 \%$ but in $5^{\text {th }}$ warmest position. Whilst in third position with a $44 \%$ chance is $1990.4^{\text {th }}$ warmest position is taken by the year 1983 with about $56 \%$ chance. These results show that when compared with the overheating occurrence ranking probabilities over $28^{\circ} \mathrm{C}$ (Figure 4), the differences for the years 1989, $1990 \& 1983$ are significant. This indicates that overheating occurrence and severity for a particular year are not always consistent.

Fig 8 C3 Ranking probability by the number of accumulated degree hours over $28 \mathrm{C}$ for Living rooms

Figures 9 to 11 show the ranking probabilities by counting the number of accumulated degree hours over adaptive comfort temperature limits. Again 1976 is consistently the warmest, and overall the year 1995 is the second warmest, but its probability decreases from over $75 \%$, to just below $75 \%$, then to about $60 \%$ (in Figures $9,10 \& 11$ ). The same is true for the year 1989 of being the third warmest but its probability is no higher 
than $50 \%$. There is a small exception for Category III upper limit (Figure 11) where the year 1990 can become the warmest $(0.5 \%$ or so) for some specific cases. Closer examinations of cases when year 1976 was not ranked the warmest did not disclose any particular pattern in terms of combinations of various conditions illustrated in table 5.

Fig 9 C11 Ranking probability by the number of accumulated degree hours over adaptive Category I for Living Rooms

Fig 10 C13Ranking probability by the number of accumulated degree hours over adaptive Category II for Living Rooms

Fig 11 C15 Ranking probability by the number of accumulated degree hours over adaptive Category III for Living Rooms

When ranking the 20 years source weather using the indoor warmth indicators such as 'the number of hours over' either $28^{\circ} \mathrm{C}$ or limiting temperatures from adaptive approach (categories I, II \& III), there are model cases in which more than one year among the 20 years source weather 'the number of hours over' is zero. It is not possible to rank these years in the same way as other years where 'the number of hours over' is positive. In such cases, when 'the number of hours over' is zero, that particular year will be counted as 'least warm' $20^{\text {th }}$ ranking position. This has made the $20^{\text {th }}$ ranking position unrealistic as the probability can be well above $100 \%$ as it includes the counting for ranked position (all positive 'number of hours over' for 20 years), as well as those cases where 'the number of over' is zero. For example, in Figures $7 \& 11$, where the sums of the years 1978 and 1988 at the $20^{\text {th }}$ position are well over $100 \%$ already, and other years still add up on this ranking position. For the year of 1995, the majority of cases for this year is ranked towards the 'warmest' side, but it does appear on the $20^{\text {th }}$ position as well (for these particular cases, the 'number of hours over' is 0 for all other years apart from year 1976). This only happens when the 'number of hours over' is zero, which explains the 'split' nature of those probabilities, i.e. for the years of 1983, 1984, 1989, 1992, 1994, in Figures 7 \& 11.

\subsection{Comparisons between outdoor warmth and indoor warmth}

Table 4 shows a list of metrics to rank the outdoor warmth. Ideally, the indoor warmth, predicted by the random building samples, can be ranked in sequence against the 20 year source weather data, i.e. using the highest probability of each year to rank these source weather years (Figures 4 to 11), and then a side by side comparisons with outdoor warmth ranking can be made. This indoor warmth ranking is found difficult to be made due to a number of reasons. Broadly, apart from the year 1976, which holds the warmest ranking position consistently, all the other years were not able to keep that level of statistical significance for all the used criteria (Figures 4 to 11), or, for some criteria, they can hold their position consistently (i.e. year 1994 in Figures 4 \& 9, year 1995 in Figure 8); for other criteria, they simply cannot. For those years positioned 'mid ranges', their highest probabilities are generally lower than $40 \%$ and very much scattered, therefore not able to be considered as statistically significant. Some year may have highest probabilities for two ranking positions, i.e. year 1983 in figure 10, it has 
the highest probability for both $4^{\text {th }}$ and $5^{\text {th }}$ position compared with year 1990 and 1989. These observations clearly demonstrate the random nature of indoor warmth prediction for majority of the source weather years (excluding the warmest year 1976), in other words, the outdoor warmth defined by weather parameters such as DBT, it does not necessarily correlate the indoor warmth consistently as different building designs perform differently against these weather parameters.

The ranking order in Table 7 is based on the averaged indoor warmth prediction for all the sample cases using the criteria discussed in section 4.2. It is an arithmetic average which mirrors the averaged DBT in Table 4. However, other than the years of 1976, $1995 \& 1989$ they do not seem to be correlating. The former chosen year of 1989 by CIBSE Guide $\mathrm{J}^{22}$ was fairly consistent for being the third warmest (mid-year of the upper quartile rule $2,33,55$ ). Even so, this is not really suggesting the averaged DBT metric is the best indicator to represent outdoor warmth as the overall consistency in terms of ranking orders for the 20 years source weather between the outdoor warmth (Table 4) and the indoor predicted warmth (Table 7) is not maintained. Moreover the | proposed ranking metric of WCDH from CIBSE TM49 ${ }^{\mathbf{1 0 9}}$ in Table 4 does not show better consistency against Table 7 as well as the probability ranking in Figures 4 to 11 . The same is also true for the proposed ranking metric 'sol-air temperature' in this research.

It is expected the sol-air temperature would be a preferred metric to indicate the outdoor warmth as it takes into account solar radiation as well as wind condition. However, no particular merits were shown when comparing this ranking metric against the predicted indoor warmth. The possible reason could be that this sol-air temperature is calculated on horizontal surface to represent its overall influence. Different building façades would normally receive uneven solar radiation, the proposed calculation mechanism is not able to reflect this (it is unlikely possible as this would be building model subjective). For wind conditions, the calculation of sol-air temperature could only reflect wind speed but not wind direction. The averaged sol-air temperature from April to September was used to rank the source weather years. This arithmetic average, the same as the averaged DBT metric, will also have the limitations i.e. such as problems of averaging and distributions. ${ }^{\mathbf{6} 6}$ These are the inherent limitations of sol-air temperature metric proposed in this study, however, solar radiation and wind speed and direction are no doubt the influencing factors to the indoor warmth prediction, other more appropriate metrics should be sought whereby solar radiation and wind conditions can be more appropriately included on top of the outdoor DBT. It is worth noting that the outdoor DBT is 'universal' to building models, different building surfaces and directions would experience the same DBT at any given time, which is the unique nature of this parameter compared with solar radiation and wind. 
In a couple of instances the year 1994 seems to maintain its ranking position surprisingly well as shown in Figures $4 \&$ 9. This is also reflected in Table 6 where it is consistently in the $6^{\text {th }}$ places in terms of arithmetically averaged indoor warmth. Detailed analysis on the characteristics of its parameters such as temperature, solar radiation and wind would be helpful to identify the underlying reasons for such phenomena. This would naturally involve statistical analysis on these parameters against other source weather years which is deemed outside the scope of this research, will be pursued at the next stage by investigating the sensitivity of weather parameters on indoor overheating prediction.

TRY is not the focus of this research but this composite year is maintaining its ranking position well in terms of averaged overheating occurrence and severity in Table 7 (TRY is consistently the $9^{\text {th }}$ from the warmer end) which does seem to show the merits of the | statistical averaging method used for creating TRY. ${ }^{87,1616}$ It is likely a composite year of DSY may relatively represent near extreme better, for example, choosing 6 near extreme months April to September statistically from the same source weather years and replace these months in TRY to form a DSY composite year. At least, this composite year of DSY will be consistent with its corresponding TRY, i.e. eliminating the possibility of TRY being warmer than DSY. The other observation is that this TRY is not exactly ranked in the middle of the 20 source weather years (exact middle ranking should be $11^{\text {th }}$ ). This may be due to the equal weighting factors used for the three parameters (DBT, solar radiation \& wind) when choosing the most representative months. $\underline{87}$

\subsection{Reflections on existing CIBSE approaches of selecting DSYs}

This research was set to argue the former and latest approaches of CIBSE on choosing Design Summer Year weather data. The former DBT averaged approach had limitations which were well documented lately. ${ }^{3,5,6}$ The latest approach of using the metric of Weight Cooling Degree Hours (WCDH) has clear merits compared with the DBT averaged approach as it 'more closely reflects the duration and severity of conditions likely to cause thermal discomfort'. However the numerical verification exercises this research performed did not seem to fully confirm this as the outdoor warmth ranked by WCDH does not correlate the predicted indoor warmth through various type of building models (dwellings only in this research), neither any other existing metrics nor the newly proposed sol-air temperature metric. In CIBSE TM49, the metric of WCDH was used to rank the source weather years, but the selection of Design Summer Year weather was no longer using the 'mid-upper quartile' rule. Instead, three complete weather years were chosen from a larger source weather years (1950 to 2006) to represent different weather characteristics in terms of warmth: Year 1989 (pDSY-1) represents a moderately warm summer, Year 2003 (pDSY-2) is a year which has a more intense single warm spell with two weeks extreme heatwave, and Year 1976 (pDSY-3) is a year with a persistent warmth summer. Besides the limitation of not considering solar radiation and wind conditions, this does appear to be a rounded approach to assess potential overheating risk in buildings by using a broader range of climate conditions. Following the analysis of likely return period in TM49, over the next 30 years (2010 to 
2040) these three pDSYs should be used to assess overheating in buildings and their morphed counterparts can be used after 2040. The indoor warmth predictions from this research (Figures 4 to 11) indicates that the overheating risk based decision can be most likely determined by the year of 1976 due to its high probability of being the warmest. The year of 2003 (not assessed in this research due to availability of weather data) could be useful to identify impact of sudden heat waves, while the year of 1989 is less likely to be used to make informed decisions.

The intention of TM49 is to investigate the sensitivity of a design by using multiple warm weather years as it is difficult to prejudge the impact of warm weather conditions on a building. If this prejudgement could be made then single warm weather could provide overheating risk based decisions for building designs. The methods used in this work could offer opportunities to make this kind of prejudgement. This will involve a large model data base with detailed descriptions of building design characteristics (i.e. parameters in table 5 but not limited to it). By evaluating their sensitivities on different warm weather conditions, these building designs can be categorized against a particular warm weather. Further research on these would provide insights on the use of these pDSYs and the likelihood of using single warm weather.

\section{Conclusions}

This research proposed a new outdoor warmth ranking metric - solar air temperature which is an artificial temperature reflecting the influence of DBT, solar radiation and wind. It was assumed this parameter would better reflect outdoor warmth over other DBT only ranking metrics which were used to select Design Summer Year weather, i.e. the averaged DBT and the weighted cooling degree hours from April to September. Multiple dwelling models and their variations were used to examine the correlation between outdoor warmth judged by various metrics and the predicted indoor warmth through these models. The indoor warmth of the 20 source weather years from 1976 to 1995 was evaluated against both overheating occurrence and severity from CIBSE Guide A and BS EN 15251 by using the predicted operative temperature. The ranking of the indoor warmth of these source weather years was made by the probability of occurrence at a particular ranking position for a particular weather year.

It is found that the predicted indoor warmth is mostly arbitrary in nature as none of the outdoor ranking metrics (neither the newly proposed solar air temperature, nor the preferred adaptive comfort based weighted cooling degree hour metric from TM49) discussed in this research correlate strictly with the predicted indoor warmth. It is evident from this research that a strict correlation between indoor warmth and outdoor warmth is unlikely possible using the random building models and the various ranking methods discussed in this research. This research provided first hand evidence to demonstrate that the thermal response of a building model is not only depending on a particular weather but also the built forms and operation. It is therefore useful to statistically evaluate the indoor warmth using the wider spectrum of weather years and large representative model samples. This can determine the likelihood of warmer years and then decide upon which years can be statistically selected for design summer year weather. It is also evident from the indoor warmth prediction in this research, even these warmer years can shift their ranking positions (i.e. the year1976 is not always the 
warmest based on the predicted indoor warmth), therefore it is difficult to apply the rule of 'mid upper quartile weather year' to select DSY as it is unlikely any 'complete' year of weather can hold a particular ranking position consistently.

The research also discovers the significant differences between overheating occurrence and severity as the ranking position of some source weather years can be quite different (i.e. 1989, $1990 \& 1983$ ). A combined approach of using multiple parameters to judge overheating, as suggested by CIBSE TM52, would therefore be able to offer better informed decision making.

For averaged overheating occurrence and severity, the predicted indoor warmth from TRY does sustain consistent ranking position. This observation suggests the likelihood of using a composite year of DSY to better represent near extreme weather. It is also worth noting that this arbitrary nature of the predicted indoor warmth through large set of building models are helpful to reassure the recent practice of CIBSE TM 49. In this Technical Memorandum, multiple warm weather years were selected to represent DSY as a single complete year may not be representative for overheating risk based decision making due to the arbitrary thermal response of various building models.

\section{Appendix A}

A more sophisticated procedure to obtain sol-air temperature is discussed in CIBSE Guide $\mathrm{J}$ where an absolute surface temperature $T_{s}(\mathrm{~K})$ is introduced, using horizontal surfaces as an example:

$\alpha_{s} I_{g}+\Delta R=h_{c}\left(T_{s}-T_{a}\right)+E$

Where $\alpha_{s}$ is the absorptivity, $I_{g}$ is the global irradiation, and $\Delta R$ is the net difference between the long-wave incident radiation from the SKY and surroundings and the radiation emitted by a black body at ambient temperature $T_{a}$ (the absolute atmospheric temperature in Kelvin), $E$ is the rate of energy flow into construction $\left(\mathrm{W} / \mathrm{m}^{2}\right)$, and $h_{c}$ is the convective heat transfer coefficient $\left(\mathrm{W} / \mathrm{m}^{2} \mathrm{~K}\right)$, can be estimated using the wind speed:

$h_{c}=4+4 v$

Where $v$ is the measured wind speed, can be obtained from weather data.

The expression for $\Delta R$ can be written as:

$\Delta R=\varepsilon\left(R_{s k y}-\sigma T_{s}^{4}\right)$

Where, $\varepsilon$ is the long-wave surface emissivity, $\sigma$ is the Sefan-Boltzmann constant $\left(5.6697 \times 10^{-8}\right), R_{s k y}$ and is the daytime sky long-wave irradiance from the atmosphere falling on a horizontal surface, defined as: 
$R_{\text {sky }}=\sigma T_{a}^{4}\left[0.904-\left(0.304-0.061 p_{w^{\frac{1}{2}}}\right) S_{h}-0.005 p_{w}{ }^{1 / 2}\right]$

Where, $S_{h}$ is the sunshine fraction which correlates the hourly cloud cover $N_{h}$ (in oktas, available within source weather files). During night time as well as the first and the last hour of daylight, the sunshine fraction and the cloud cover are correlated by:

$S_{h}=1-\frac{N_{h}}{8}$

While during the daytime, the sunshine fraction and the cloud cover have a secondorder banded polynomial relationship, as below: ${ }^{27}$

$S_{h}=1 \mid N_{h} \leq 1$ or $S_{h}>1$

$S_{h}=a_{0}+a_{1} N_{h}+a_{2} N_{h}{ }^{2} \mid 1<N_{h}<8$

$S_{h}=0 \mid N_{h}=8$

The coefficients of $a_{0}, a_{1} a_{2}$ and are determined by the solar altitude (degrees), as shown in Table A1

Table A1: Solar altitude banded coefficients ${ }^{27}$

\begin{tabular}{|l|c|c|c|c|c|c|}
\hline & \multicolumn{7}{|c|}{ Solar altitude (degrees) } \\
\cline { 2 - 7 } & $8-15$ & $15-25$ & $25-35$ & $35-45$ & $45-55$ & Above 55 \\
\hline$a_{0}$ & 1.0410 & 0.9800 & 0.9700 & 0.9430 & 0.9080 & 0.9030 \\
\hline$a_{1}$ & -0.0881 & -0.0074 & 0.0413 & 0.0900 & 0.1237 & 0.1209 \\
\hline$a_{2}$ & -0.0059 & -0.0148 & -0.0209 & -0.0263 & -0.0299 & -0.0286 \\
\hline
\end{tabular}

$p_{w}$ in equation (A04) is the water vapour pressure ( $\mathrm{hPa}$ : hectopascal $\left.=100 \mathrm{~Pa}\right)$, defined using the work of Martinez (1994) ${ }^{28}$

$p_{w}=p_{w b t}-k p_{a t o}\left(t_{a}-t_{w b t}\right)$

Where, $k$ is a constant, taken as $6.53 \times 10^{-4}\left(1 /{ }^{\circ} \mathrm{C}\right) ; t_{w b t}$ is the environment wet bulb temperature $\left({ }^{\circ} \mathrm{C}\right) ; p_{a t o}$ is the atmosphere pressure $(\mathrm{hPa})$, and $p_{w b t}$ is written in the form of the following empirical expression using $t_{w b t}{ }^{29}$ :

$p_{w b t}=C \exp \left(\frac{A t_{w b t}}{B+t_{w b t}}\right)$

Where the coefficients of $A, B, \& C$ are given by the work of Alduchov \& Eskridge $(1996)^{[30]}: A=17.625, B=243.04\left({ }^{\circ} \mathrm{C}\right)$, and $C=6.11(\mathrm{hPa})$

To close the equation set (02 to 08), the rate of energy flow in equation (02) is assumed to be $0\left(\mathrm{~W} / \mathrm{m}^{2}\right)$ (on the assumption of highly insulated horizontal surface, i.e. a flat roof). Therefore $T_{S}$ can be obtained by solving equations ( 02 to 08 , effectively the equation below):

$\varepsilon \sigma T_{s}^{4}+h_{c} T_{s}-\left(\alpha_{s} I_{g}+\varepsilon R_{s k y}+h_{c} T_{a}\right)=0$ 
and the sol-air temperature, $t_{s a}$ is defined as:

$$
t_{s a}=T_{s}-273.15
$$

\section{References}

${ }^{1}$ CIBSE Guide A. Environmental Design, London: The Chartered Institution of Building Services Engineers, 2006, ISBN-13: 978-1-903287-66-8.

${ }^{2}$ CIBSE Guide J. Weather, solar and illuminance data, London: The Chartered Institution of Building Services Engineers London, 2002, ISBN 190328712 X.

${ }^{3}$ Nicol J, Hacker J, Spires B \& Davies H. Suggestion for new approach to overheating diagnostics. Building Research \& Information, 2009; 37(4), pp. 348-357.

${ }^{4}$ CIBSE TM48. Use of climate change scenarios for building simulation: the CIBSE future weather years, London: The Chartered Institution of Building Services, 2009; ISBN 978-1-906846-01-5.

${ }^{5}$ Smith S T \& Hanby V. Methodologies for the generation of design summer years for building energy simulation using UKCP09 probabilistic climate projections. Building Serv. Eng. Res. Technol., 2012; 33(1), pp. 9-17.

${ }^{6}$ Jentsch M F, Levermore G J, Parkinson J B \& Eames M E. Limitations of the CIBSE design summer year approach for delivering representative near-extreme summer weather conditions. Building Serv. Eng. Res. Technol., 2014; 35(2), pp. 155-169.

${ }^{7}$ Watkins R, Levermore GJ \& Parkinson JB. The design reference year - a new approach to testing a building in more extreme weather using UKCP09 projections. Building Services Engineering Research and Technology, 2011; 34(2), pp. 165-176.

8 Levermore G \& Parkinson J. Analyses and algorithms for new Test Reference Years and Design Summer Years for the UK. Building Services Engineering Research and Technology, 2006; 27(4), pp. 311-325

${ }^{9}$ CIBSE TM41. Degree days - theory and application. London: Charted Institution of Building Services Engineers; 2006.

${ }^{10}$ CIBSE TM49. Design Summer Years for London, The Chartered Institution of Building Services Engineers London. 2014; ISBN 978-1-906846-27-5.

${ }^{11}$ BS EN 15251. Indoor environmental input parameters for design and assessment of energy performance of buildings addressing indoor air quality, thermal environment, lighting and acoustics. 2007; BSI, EN 15251:2007 (E).

${ }_{12}^{12}$ O'Callaghan P W \& Probert S D. Sol-air temperature. Applied Energy, 1977; vol 3 (4), pp 307-311.

${ }^{13}$ Thakur A K S. Exact expression for solair temperature. Journal of Physics D: Applied Physics, 1989; vol 22, pp 470-471.

${ }^{14}$ Recep Yumrutaş, Önder Kaşka, Erdal Yıldırım. Estimation of total equivalent temperature difference values for multilayer walls and flat roofs by using periodic solution, Building and Environment, 2007; Vol 42(5), pp 1878-1885

${ }^{15}$ Celestino R. Ruivo, Paulo M. Ferreira \& Daniel C. Vaz. Prediction of thermal load temperature difference values for the external envelope of rooms with setback and setup thermostats. Applied Thermal Engineering, 2013; Vol 51 (1-2), pp. 980-987

${ }^{16}$ Finkelstein J M \& Schafer R.E. Improved goodness of fit tests. Biometrika 1971, vol. 58, iss. 3, pp. 641-645,

${ }^{17}$ UrbanArea 2012. Vanguard6 Passivhaus Proposal for East Midlands Housing Group [Online]. Available at: http://www.urbanarea.co.uk/Vanguard6.html [Accessed: 08 February 2015].

${ }^{18}$ Korolija K \& Zhang Y. Impact of model simplication on energy and comfort analysis for dwellings. Proceedings of BS2013, the $13^{\text {th }}$ conference of IBPSA, Chambery, France, August 26-28, 2013.

${ }^{19}$ Zhang Y. "Parallel" EnergyPlus and the development of a parametric analysis tool. 11th International IBPSA Conference, pp 1382-1388, July 27-30, 2009, Glasgow, Scotland.

${ }^{20}$ Stein M. Large Sample Properties of Simulations Using Latin Hypercube Sampling Technometrics,1987; vol 29, no.2, pp.143-151. 
${ }^{21}$ Lomas K J \& Ji Y. Resilience of naturally ventilated buildings to climate change: Advanced natural ventilation and hospital wards. Energy and Buildings, 2009; Vol 41, Iss 6, p. 629-653, http://dx.doi.org/10.1016/j.enbuild.2009.01.001

${ }^{22}$ Peacock A D, Jenkins D P \& Kane D. Investigating the potential of overheating in UK dwellings as a consequence of extant climate change. Energy Policy, 2010; Vol 38, Iss 7, P. 3277-3288,

http://dx.doi.org/10.1016/j.enpol.2010.01.021

${ }^{23}$ Short C A, Lomas K J, Giridharan R \& Fair A J. Building resilience to overheating into 1960's UK hospital buildings within the constraint of the national carbon reduction target: Adaptive strategies. Building and Environment, 2012; Vol 55, Pages 73-95, http://dx.doi.org/10.1016/j.buildenv.2012.02.031

${ }^{24}$ Ji Y, Fitton R, Swan W \& Webster P. Assessing overheating of the UK existing dwellings - A case study of replica Victorian end terrace house. Building and Environment, 2014; Vol 77, P. 1-11, http://dx.doi.org/10.1016/j.buildenv.2014.03.012

${ }^{25}$ Humphreys M A \& Nicol J F. Understanding the adaptive approach to thermal comfort. ASHRAE Trans 1998; Vol 104, Iss 1, pp. 991 to 1004.

${ }^{26}$ CIBSE TM52. The Limits of thermal comfort avoiding overheating in European buildings. ISBN 9781-906846-34-3, (C) July 2013 The Chartered Institution of Building Services Engineers London.

${ }^{27}$ Muneer T \& Fairooz F. Quality control of solar radiation and sunshine measurements - lessons learnt from processing worldwide database. Building Serv. Eng. Res. Technol. 2002; Vol. 23 (3), pp.151-166.

${ }^{28}$ Martinez A T. On the evaluation of the web bulb temperature as a function of dry bulb temperature and relative humidity. Journal of Atmósfera, 1994; vol 7, pp. 179-184.

${ }^{29}$ Gibbins C J. A survey and comparison of relationships for the determination of the saturation vapour pressure over plan surfaces of pure water and pure ice. Journal of Annales Geophysicae, 1990; vol 8, pp 859-885.

${ }^{30}$ Alduchov O A \& Eskridge R E. Improved Magnus form approximation of saturation vapour pressure. Journal of Applied Meteorology, 1996; vol 35 (4), pp. 601-609. 
Table 1 Number of hours over (HO) and accumulated degree hours (ADH) over fixed temperatures and for the 20 years (L76 - L95 is London 1976 - 1995) source weather data and their TRY

\begin{tabular}{|c|c|c|c|c|c|c|c|c|c|c|c|c|c|c|}
\hline \multirow{2}{*}{$\begin{array}{c}\text { Deg. } \\
\text { year }\end{array}$} & \multicolumn{2}{|c|}{$>22^{\circ} \mathrm{C}$} & \multicolumn{2}{c|}{$>23^{\circ} \mathrm{C}$} & \multicolumn{2}{c|}{$>24^{\circ} \mathrm{C}$} & \multicolumn{2}{c|}{$>25^{\circ} \mathrm{C}$} & \multicolumn{2}{c|}{$>26^{\circ} \mathrm{C}$} & \multicolumn{3}{c|}{$>27^{\circ} \mathrm{C}$} & \multicolumn{3}{c|}{$>28^{\circ} \mathrm{C}$} \\
\hline L95 & 666 & 2449 & 544 & 1841 & 429 & 1352 & 335 & 963.3 & 255 & 663.1 & 190 & 440.4 & 138 & 271.1 \\
\hline L94 & 429 & 1254 & 319 & 871.3 & 228 & 592.5 & 167 & 392.4 & 117 & 247.6 & 76 & 150.2 & 52 & 85.6 \\
\hline L93 & 239 & 460.1 & 150 & 259.6 & 94 & 137.6 & 54 & 61.7 & 25 & 21.5 & 8 & 4.2 & 0 & 0 \\
\hline L92 & 375 & 806.2 & 250 & 487.4 & 168 & 272.4 & 105 & 131.7 & 46 & 54.5 & 21 & 19 & 8 & 5.6 \\
\hline L91 & 385 & 746 & 249 & 415.7 & 140 & 218 & 83 & 103.5 & 41 & 39.3 & 15 & 11 & 4 & 2.9 \\
\hline L90 & 526 & 1792 & 413 & 1315 & 317 & 947.6 & 237 & 664.1 & 171 & 454.8 & 106 & 310.8 & 75 & 222.1 \\
\hline L89 & 634 & 1935 & 496 & 1363 & 391 & 910.2 & 267 & 570.5 & 179 & 341 & 107 & 199 & 63 & 109.6 \\
\hline L88 & 133 & 254.3 & 82 & 144.9 & 51 & 79 & 30 & 39.7 & 15 & 17.1 & 7 & 6.3 & 3 & 1.8 \\
\hline L87 & 243 & 556.6 & 169 & 349.3 & 112 & 207.4 & 69 & 117.6 & 46 & 60.4 & 28 & 22.4 & 8 & 4.5 \\
\hline L86 & 202 & 598.5 & 150 & 415.8 & 118 & 278.7 & 85 & 174.1 & 58 & 98 & 35 & 49.7 & 21 & 21.1 \\
\hline L85 & 170 & 353.8 & 115 & 206.4 & 73 & 111.7 & 40 & 55.5 & 18 & 24 & 9 & 9.8 & 4 & 2.6 \\
\hline L84 & 418 & 1039 & 297 & 672.9 & 197 & 422.6 & 140 & 251.3 & 76 & 139.4 & 51 & 76.1 & 29 & 34.3 \\
\hline L83 & 543 & 1758 & 428 & 1263 & 328 & 872.7 & 237 & 585 & 170 & 373.6 & 112 & 232.2 & 68 & 139.9 \\
\hline L82 & 362 & 773.5 & 243 & 470.1 & 165 & 264.6 & 100 & 129.7 & 47 & 54.1 & 20 & 17.4 & 6 & 3.4 \\
\hline L81 & 265 & 542.3 & 180 & 317.1 & 108 & 166.5 & 61 & 76.9 & 29 & 29.9 & 12 & 9.8 & 5 & 1.7 \\
\hline L80 & 175 & 316.5 & 111 & 170.7 & 56 & 80.5 & 25 & 38.3 & 15 & 17.9 & 9 & 6.6 & 2 & 0.8 \\
\hline L79 & 205 & 420.6 & 130 & 248.8 & 96 & 134.3 & 51 & 58.6 & 15 & 24.3 & 8 & 13.1 & 6 & 6.6 \\
\hline L78 & 154 & 255.7 & 100 & 127.8 & 52 & 48.9 & 16 & 11.7 & 3 & 1.2 & 0 & 0 & 0 & 0 \\
\hline L77 & 154 & 335.6 & 101 & 201 & 70 & 116.8 & 46 & 58 & 26 & 22.2 & 10 & 3.8 & 0 & 0 \\
\hline L76 & 702 & 2704 & 560 & 2063 & 463 & 1547 & 350 & 1136 & 259 & 826.6 & 207 & 591 & 164 & 403.8 \\
\hline TRY & 342 & 893.5 & 257 & 587.2 & 186 & 363.3 & 121 & 209.5 & 69 & 108.7 & 38 & 51.4 & 21 & 20.8 \\
\hline
\end{tabular}

Table 2 Weighted Cooling degree hours $(\mathrm{WCDH})$ and accumulated degree hours over $\mathrm{T}_{\text {comf }}$ (ADHC) for London.

\begin{tabular}{|c|c|c|c|c|c|c|c|c|c|c|c|c|c|c|c|c|c|c|c|c|c|}
\hline Year & L95 & L94 & L93 & L92 & L91 & L90 & L89 & L88 & L87 & L86 & L85 & L84 & L83 & L82 & L81 & L80 & L79 & L78 & L77 & L76 & TRY \\
\hline $\begin{array}{c}\text { WCD } \\
\text { H }\end{array}$ & 3060 & 1277 & 169 & 397 & 240 & 2738 & 1808 & 163 & 339 & 604 & 198 & 850 & 1527 & 376 & 247 & 275 & 275 & 65 & 175 & 3972 & 727 \\
\hline $\begin{array}{c}\text { ADH } \\
\text { C }\end{array}$ & 807 & 359 & 97 & 188 & 120 & 622 & 572 & 68 & 140 & 205 & 89 & 285 & 457 & 176 & 121 & 97 & 119 & 47 & 87 & 921 & 270 \\
\hline
\end{tabular}

Table 3 Averaged April to September sol-air temperatures

\begin{tabular}{|c|c|c|c|c|c|c|c|c|c|c|c|c|c|c|c|c|c|c|c|c|}
\hline & L76 & L77 & L78 & L79 & L80 & L81 & L82 & L83 & L84 & L85 & L86 & L87 & L88 & L89 & L90 & L91 & L92 & L93 & L94 & L95 \\
\hline tsa & 29.9 & 25.4 & 25.8 & 26.2 & 26.5 & 26.1 & 27.5 & 27.8 & 27.6 & 26.4 & 25.7 & 26.4 & 26.0 & 29.4 & 28.8 & 26.9 & 27.7 & 26.8 & 27.6 & 29.3 \\
\hline t'sa & 21.0 & 16.6 & 17.2 & 17.7 & 17.6 & 18.0 & 19.5 & 19.3 & 19.3 & 17.9 & 17.7 & 18.4 & 17.7 & 20.9 & 19.9 & 18.8 & 19.9 & 18.8 & 19.3 & 20.5 \\
\hline 'sa & 21.4 & 17.6 & 18.0 & 18.3 & 18.6 & 18.4 & 19.5 & 19.7 & 19.4 & 18.5 & \begin{tabular}{|l}
17.8 \\
\end{tabular} & 18.6 & 18.2 & 21.0 & 20.4 & 19.0 & 19.7 & 18.9 & 19.6 & 21.0 \\
\hline
\end{tabular}


Table 5 Parameters and considered settings

\begin{tabular}{|c|c|c|}
\hline Parameters & Settings & $\begin{array}{l}\text { No of } \\
\text { changes }\end{array}$ \\
\hline House types & $\begin{array}{l}\text { Detached ( } 2 \text { sizes), semi-detached (1 size) \& terraced ( } 2 \\
\text { sizes) }\end{array}$ & 5 \\
\hline Orientation & $0-345^{\circ}$, step: $45^{\circ}$ & 8 \\
\hline Exterior wall & $\begin{array}{l}\text { Heavy weight (Brick-insulation-concrete block) } \\
\text { Medium weight (Brick-cavity-insulation-plastering) } \\
\text { Light weight (Timber-cavity-insulation-plastering) }\end{array}$ & 3 \\
\hline \multirow[t]{3}{*}{ Insulation } & Exterior wall insulation: $50-400 \mathrm{~mm}$, step: $50 \mathrm{~mm}$ & 8 \\
\hline & Roof insulation: $50-400 \mathrm{~mm}$, step: $50 \mathrm{~mm}$ & 8 \\
\hline & Ground insulation: $50-400 \mathrm{~mm}$, step: $50 \mathrm{~mm}$ & 8 \\
\hline Glazing & $\begin{array}{l}\text { Double and triple glazing with various U values, solar } \\
\text { heat gain coefficients and light transmittance }\end{array}$ & 8 \\
\hline Infiltration & 0.05 ach -0.95 ach, step: 0.1 ach & 10 \\
\hline $\begin{array}{l}\text { Natural } \\
\text { ventilation }\end{array}$ & $\begin{array}{l}0 \text { to } 24 \text { ach, step: } 6 \text { ach, adjusted by temperature } \\
\text { difference and wind speed }\end{array}$ & 5 \\
\hline Heating setpoint & Lounge $\left(18-22^{\circ} \mathrm{C}\right.$, step: $\left.1^{\circ} \mathrm{C}\right)$ & 5 \\
\hline Heating setpoint & Bedrooms $\left(16-22^{\circ} \mathrm{C}\right.$, step: $\left.1^{\circ} \mathrm{C}\right)$ & 7 \\
\hline Load fraction & Equipment $(0.5-2.0$, step: 0.5$)$ & 4 \\
\hline Load fraction & Lighting $(0.5-2.0$, step: 0.5$)$ & 4 \\
\hline $\begin{array}{l}\text { Occupant's } \\
\text { density fraction }\end{array}$ & $0.5-1.5$, step: 0.5 & 3 \\
\hline Occupancy type & Working family, constantly occupied & 2 \\
\hline Daylight control & Present, not present & 2 \\
\hline \multirow[t]{2}{*}{$\begin{array}{l}\text { Heating } \\
\text { operation }\end{array}$} & Intermittent, continuous & 2 \\
\hline & Total number of variations: & $3.3 \times 10^{11}$ \\
\hline
\end{tabular}

Table 4 Ranking orders of the 20 years source weather data (L76-L95) with various metrics (their corresponding TRY is added as a reference)

\begin{tabular}{|c|c|c|c|c|c|c|c|c|c|c|c|c|c|c|c|c|c|c|c|c|c|}
\hline \multirow{2}{*}{$\begin{array}{l}\text { Avg. } \\
\text { DBT }\end{array}$} & \multicolumn{2}{|c|}{$>21$} & \multicolumn{2}{|c|}{$>22$} & \multicolumn{2}{|c|}{$>23$} & \multicolumn{2}{|c|}{$>24$} & \multicolumn{2}{|c|}{$>25$} & \multicolumn{2}{|c|}{$>26$} & \multicolumn{2}{|c|}{$>27$} & \multicolumn{2}{|c|}{$>28$} & \multirow{2}{*}{$\mathrm{VCDH}$} & \multirow{2}{*}{$\mathrm{DHC}$} & \multirow{2}{*}{$t_{\mathrm{sa}}$} & \multirow{2}{*}{$\mathrm{t}_{\mathrm{sa}}$} & \multirow{2}{*}{ "t'sa } \\
\hline & HO & ADH & HO & ADH & HO & ADH & HO & ADH & $\mathrm{HO}$ & ADH & HO & ADH & HO & ADH & HO & ADH & & & & & \\
\hline L77 & L77 & 38 & L88 & L88 & L88 & L78 & 88 & 88 & L78 & 8 & L78 & 78 & L78 & 78 & L93 & L93 & 78 & L78 & 77 & 77 & $\llcorner 77$ \\
\hline L86 & L88 & L78 & L78 & L78 & L78 & L88 & L78 & 8 & L80 & L80 & 88 & 88 & L88 & 7 & 78 & 8 & 88 & L88 & 86 & 278 & L86 \\
\hline L78 & L85 & L77 & L77 & L80 & L77 & L80 & L80 & L80 & L88 & L88 & L80 & L80 & L93 & L93 & L77 & L77 & L93 & L77 & L78 & L80 & L78 \\
\hline$\llcorner 79$ & $\llcorner 78$ & L80 & L85 & L77 & L80 & L77 & L77 & L85 & L85 & L85 & L79 & L93 & L79 & L88 & L80 & L80 & L77 & L85 & L88 & $\llcorner 79$ & L88 \\
\hline L88 & L80 & L8: & L80 & L85 & L85 & L85 & L85 & $\lfloor 77$ & $\llcorner 77$ & L77 & L85 & L77 & L85 & 80 & L88 & L8 & 80 & L80 & -81 & L86 & $\llcorner 79$ \\
\hline L85 & L86 & L79 & L86 & $\llcorner 79$ & $\llcorner 79$ & L79 & L93 & L79 & $\llcorner 79$ & L79 & L93 & L85 & L80 & L81 & L91 & L88 & L91 & L93 & L79 & L88 & L81 \\
\hline L80 & L79 & L93 & L79 & L93 & L93 & L93 & L79 & L93 & L93 & L93 & L77 & L79 & L77 & L85 & L85 & L85 & L81 & L79 & L87 & L85 & L85 \\
\hline L81 & L87 & L86 & L93 & L81 & L86 & L81 & L81 & L8 & L81 & L $\varepsilon$ & L81 & L8 & L81 & L9 & LE & L9 & L8 & L91 & -85 & 81 & L80 \\
\hline L87 & L93 & L87 & L87 & L87 & L87 & L87 & L87 & L8 & L87 & L91 & L91 & L91 & L91 & L79 & L82 & L82 & 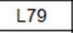 & L81 & L80 & 87 & L87 \\
\hline L91 & L81 & L81 & L81 & L86 & L81 & L91 & L86 & L91 & L91 & L87 & L92 & L82 & L82 & L82 & L79 & L87 & L87 & L87 & L93 & TRY & L93 \\
\hline L93 & TRY & L91 & TRY & L91 & L82 & L86 & L91 & L82 & L86 & L82 & L87 & L92 & L92 & L92 & L92 & L92 & L82 & L82 & L91 & $\llcorner 93$ & L91 \\
\hline TRY & L82 & L82 & L82 & L82 & L91 & L82 & L82 & L92 & L82 & L92 & L82 & L87 & L87 & L87 & L87 & L79 & L92 & L92 & TRY & L91 & TRY \\
\hline L84 & L91 & L92 & L92 & L92 & L92 & L92 & L92 & L86 & L92 & L86 & L86 & L86 & L86 & L86 & TRY & TRY & L86 & L86 & L82 & L94 & L84 \\
\hline L94 & L92 & TRY & L91 & TRY & TRY & TRY & TRY & TRY & TRY & TRY & TRY & TRY & TRY & TRY & L86 & L86 & TRY & TRY & L94 & L84 & L82 \\
\hline L82 & L94 & L84 & L84 & L84 & L84 & L84 & L84 & L84 & L84 & L84 & L84 & L84 & L84 & L84 & L84 & L84 & L84 & L84 & L84 & L83 & L94 \\
\hline L83 & L84 & L94 & L94 & L94 & L94 & L94 & L94 & L94 & L94 & L94 & L94 & L94 & L94 & L94 & L94 & L94 & L94 & L94 & L92 & L82 & L83 \\
\hline L92 & L90 & L83 & L90 & L83 & L90 & L83 & L90 & L83 & L90 & L89 & L83 & L89 & L90 & L89 & L89 & L89 & L83 & L83 & L83 & L92 & L92 \\
\hline L90 & L83 & L90 & L83 & $\llcorner 90$ & L83 & L90 & L83 & L89 & L83 & L83 & L90 & L83 & L89 & L83 & L83 & L83 & L89 & L89 & L90 & L90 & L90 \\
\hline L89 & L95 & L89 & L89 & L89 & L89 & L89 & L89 & L90 & L89 & L90 & L89 & $\mathrm{L} 90$ & L83 & L90 & L90 & L90 & L90 & L90 & $\llcorner 95$ & L95 & L89 \\
\hline L95 & L89 & L95 & L95 & L95 & L95 & L95 & L95 & L95 & L95 & L95 & L95 & L95 & L95 & L95 & L95 & L95 & L95 & L95 & L89 & L89 & L95 \\
\hline L76 & L76 & L76 & L76 & L76 & L76 & L76 & L76 & L76 & L76 & L76 & L76 & L76 & L76 & L76 & L76 & L76 & L76 & L76 & L76 & L76 & L76 \\
\hline
\end{tabular}


Table 7 Ranking orders of indoor warmth for the 20 source weather years and their TRY (by the averaged number of hours over (HO) and accumulated degree hours (ADH) over $28 \mathrm{C}$ and adaptive comfort temperature limits).

\begin{tabular}{|c|c|c|c|c|c|c|c|c|c|c|c|c|c|c|c|}
\hline \multicolumn{2}{|c|}{$>28$} & \multicolumn{2}{|c|}{$>$ Cat I } & \multicolumn{2}{|c|}{$>$ Cat II } & \multicolumn{2}{|c|}{$>$ Cat III } & \multicolumn{2}{|c|}{$>28$} & \multicolumn{2}{|c|}{$>$ Cat I } & \multicolumn{2}{|c|}{$>$ Cat II } & \multicolumn{2}{|c|}{$>$ Cat III } \\
\hline \multicolumn{2}{|c|}{$\mathrm{HO}$} & \multicolumn{2}{|c|}{$\mathrm{HO}$} & \multicolumn{2}{|c|}{$\mathrm{HO}$} & \multicolumn{2}{|c|}{$\mathrm{HO}$} & \multicolumn{2}{|c|}{$\mathrm{ADH}$} & \multicolumn{2}{|c|}{$\mathrm{ADH}$} & \multicolumn{2}{|c|}{$\mathrm{ADH}$} & \multicolumn{2}{|c|}{$\mathrm{ADH}$} \\
\hline L88 & 57 & L88 & 136 & L88 & 81 & L88 & 47 & L88 & 103 & L88 & 249 & L88 & 143 & L88 & 80 \\
\hline L80 & 68 & L77 & 137 & L77 & 86 & L77 & 53 & L80 & 126 & L77 & 281 & L77 & 171 & L80 & 103 \\
\hline L78 & 69 & L85 & 154 & L85 & 95 & L80 & 57 & L78 & 135 & L80 & 300 & L80 & 177 & L77 & 103 \\
\hline L77 & 69 & L80 & 155 & L80 & 95 & L85 & 57 & L85 & 140 & L85 & 303 & L85 & 181 & L85 & 106 \\
\hline L85 & 71 & L78 & 157 & $\mathrm{~L} 78$ & 96 & L78 & 59 & L77 & 147 & L78 & 310 & L78 & 186 & L78 & 110 \\
\hline L79 & 82 & L79 & 167 & L79 & 102 & L79 & 62 & L79 & 157 & L79 & 323 & L79 & 191 & L79 & 111 \\
\hline L81 & 91 & L87 & 171 & L81 & 109 & L81 & 64 & L81 & 171 & L81 & 338 & L81 & 197 & L81 & 113 \\
\hline L87 & 98 & L81 & 179 & L87 & 109 & L87 & 68 & L87 & 211 & L87 & 359 & L87 & 221 & L87 & 134 \\
\hline L93 & 102 & L86 & 188 & L86 & 122 & L86 & 75 & L93 & 218 & L86 & 400 & L86 & 247 & L86 & 150 \\
\hline L86 & 110 & L93 & 201 & L93 & 126 & L93 & 78 & L82 & 244 & L93 & 414 & L93 & 254 & L82 & 151 \\
\hline L82 & 122 & L82 & 220 & L82 & 136 & L82 & 83 & L86 & 250 & L82 & 433 & L82 & 258 & L93 & 154 \\
\hline L91 & 147 & L91 & 240 & L91 & 155 & L91 & 98 & L91 & 312 & L91 & 518 & L91 & 323 & L91 & 198 \\
\hline TRY & 151 & TRY & 252 & TRY & 164 & TRY & 104 & TRY & 334 & TRY & 551 & TRY & 346 & TRY & 214 \\
\hline L92 & 160 & L92 & 256 & L92 & 171 & L92 & 111 & L92 & 360 & L92 & 583 & L92 & 372 & L84 & 227 \\
\hline L84 & 168 & L84 & 275 & L84 & 181 & L84 & 115 & L84 & 363 & L84 & 597 & L84 & 372 & L92 & 233 \\
\hline L94 & 212 & L94 & 302 & L94 & 210 & L94 & 143 & L94 & 533 & L94 & 744 & L94 & 490 & L94 & 315 \\
\hline L90 & 239 & L83 & 314 & L83 & 216 & L83 & 146 & L83 & 637 & L83 & 758 & L83 & 496 & L83 & 317 \\
\hline L83 & 241 & L90 & 340 & L90 & 237 & L90 & 162 & L90 & 660 & L90 & 844 & L90 & 558 & L90 & 361 \\
\hline L89 & 297 & L95 & 400 & L89 & 286 & L89 & 193 & L89 & 764 & L89 & 1019 & L89 & 673 & L89 & 436 \\
\hline L95 & 337 & L89 & 413 & L95 & 292 & L95 & 206 & L95 & 974 & L95 & 1069 & L95 & 725 & L95 & 477 \\
\hline L76 & 353 & L76 & 432 & L76 & 317 & L76 & 227 & L76 & 1145 & L76 & 1204 & L76 & 831 & L76 & 561 \\
\hline
\end{tabular}




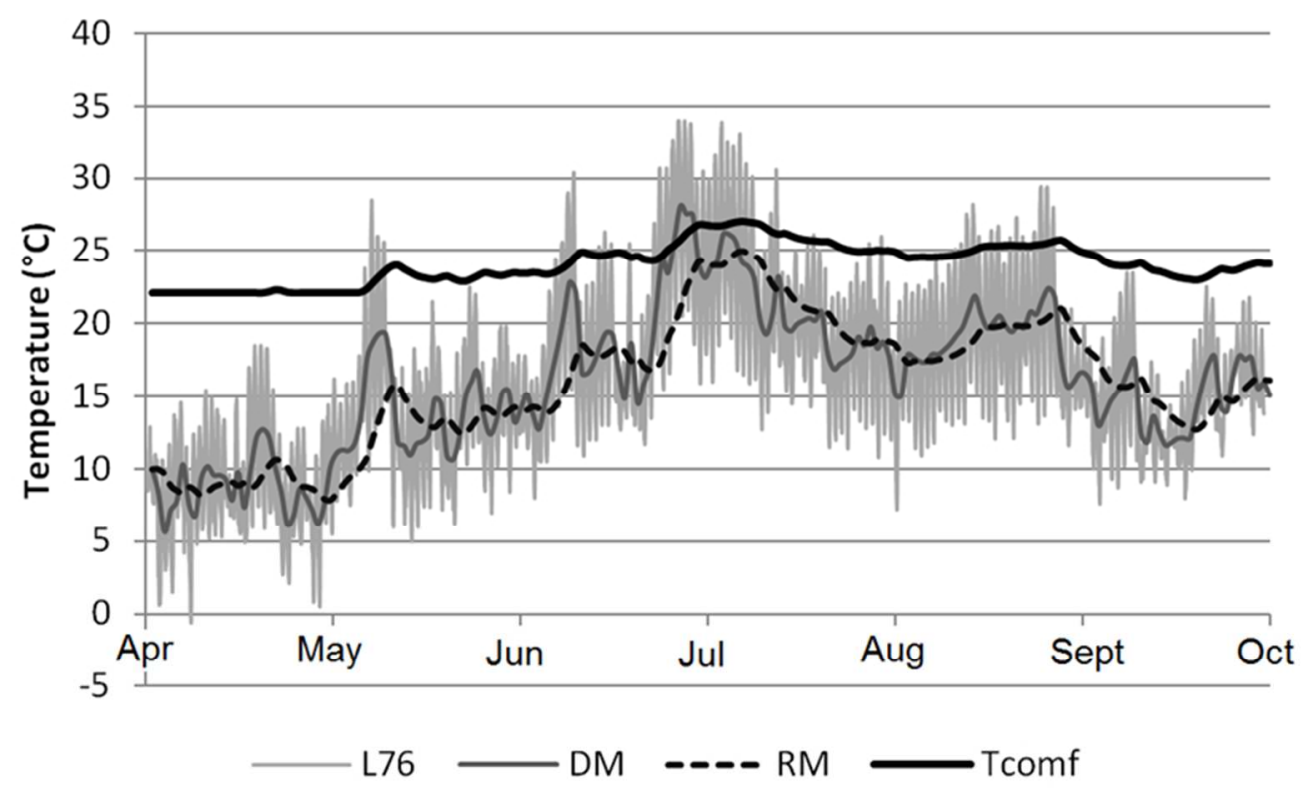

Figure 1 London Heathrow 1976 DBT data (April to September only) $69 \times 42 \mathrm{~mm}(300 \times 300$ DPI $)$ 
Figure 2 Ambient dry bulb temperature ta of London 1976 vs its sol-air temperatures calculated by Eq. 04 \& 06. $88 \times 59 \mathrm{~mm}(300 \times 300$ DPI $)$

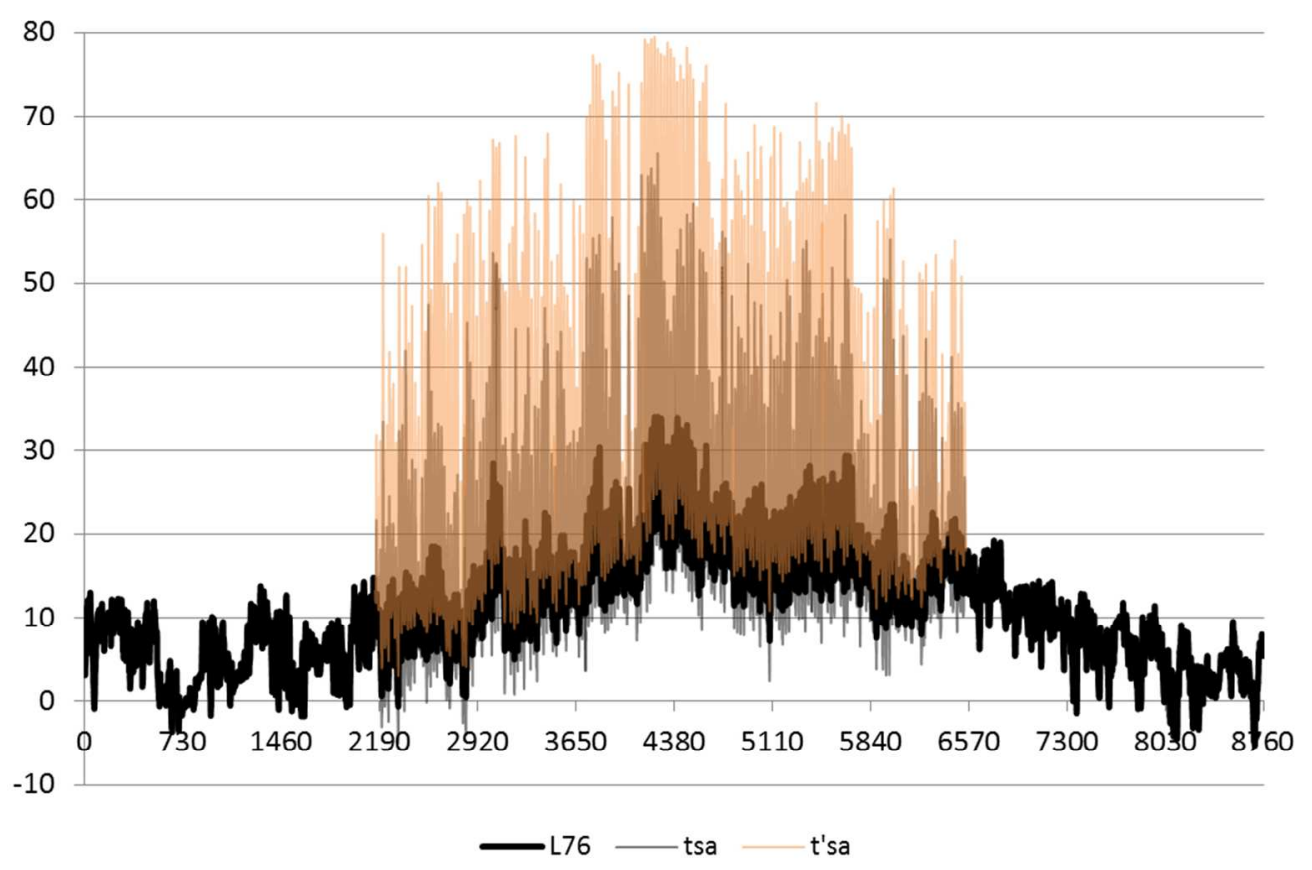



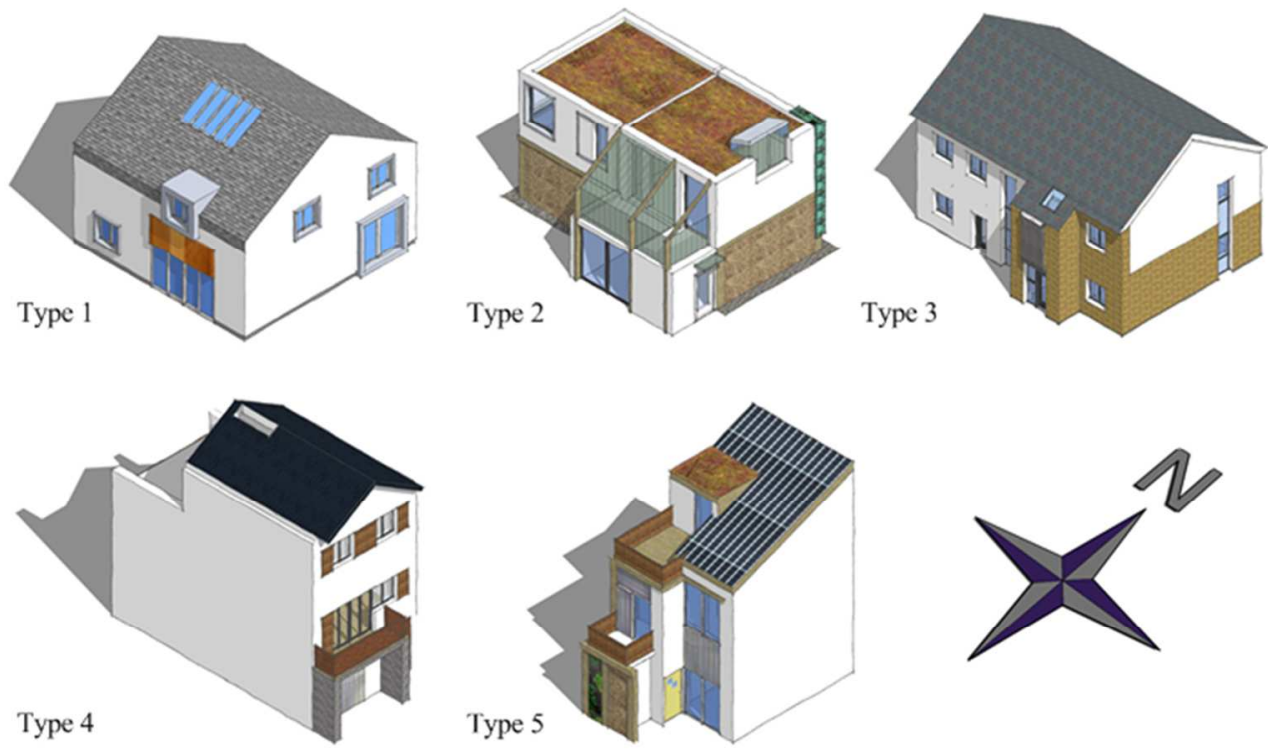

Figure 3 The five house types for numerical verification $92 \times 53 \mathrm{~mm}(300 \times 300 \mathrm{DPI})$ 


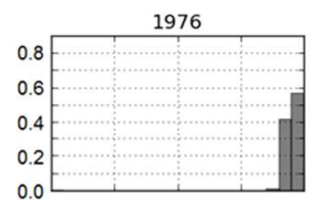

1980

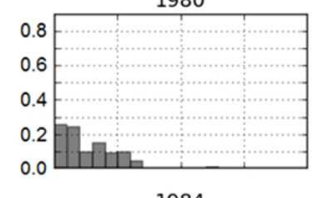

1984

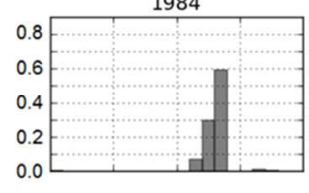

1988

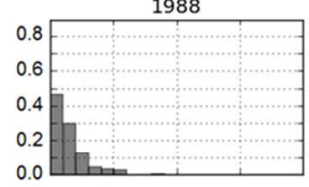

1992

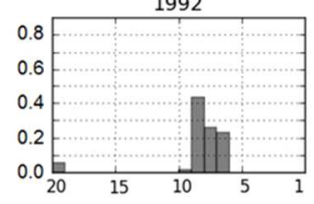

1977

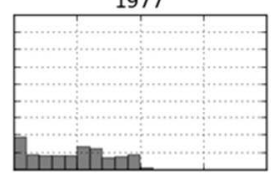

1981

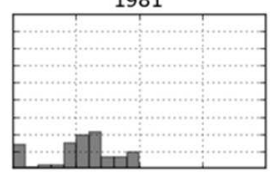

1985

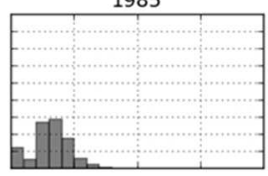

1989

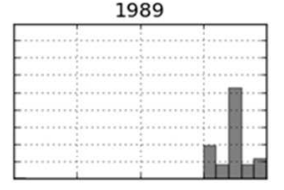

1993

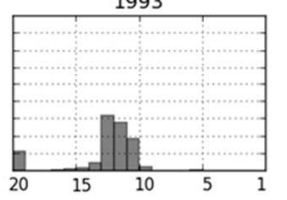

1978

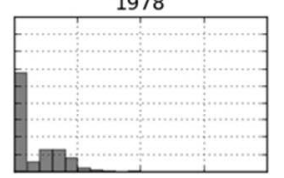

1982

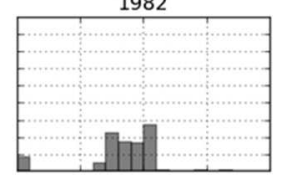

1986

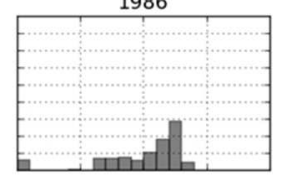

1990

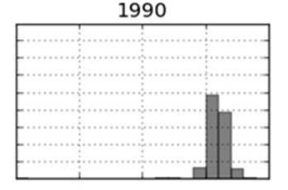

1994

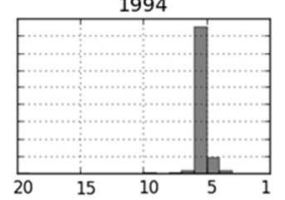

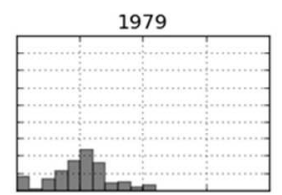

1983

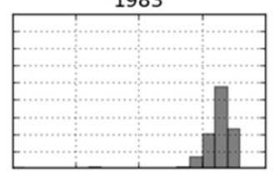

1987

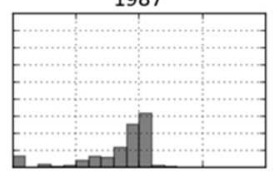

1991

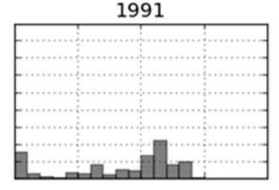

1995

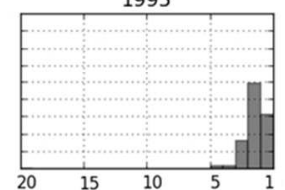

Figure $4 \mathrm{C} 1$ - Ranking probability by the number of hours over $28 \mathrm{C}$ for Living rooms while occupied ( $x$-axis is ranking position and $y$-axis is the probability of being that position for a particular year, same hereafter) $85 \times 66 \mathrm{~mm}(300 \times 300 \mathrm{DPI})$ 

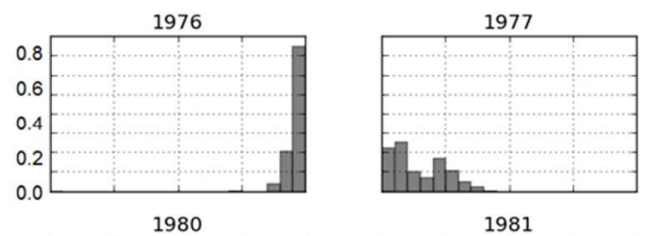

1981
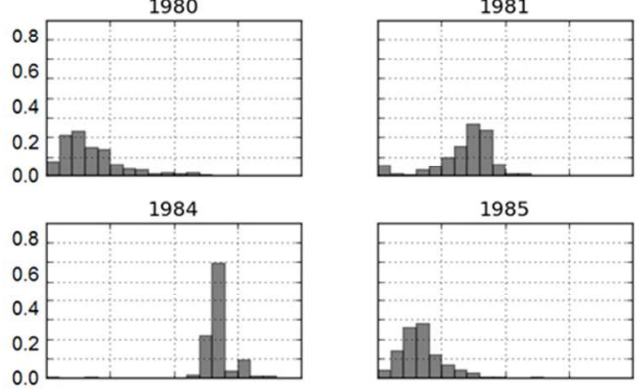

1988

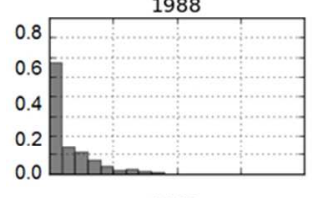

1992

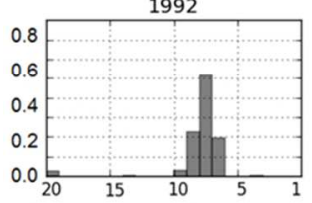

1985

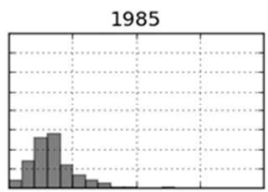

1989

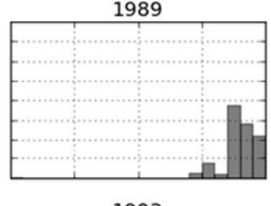

1993

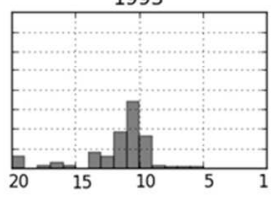

1978

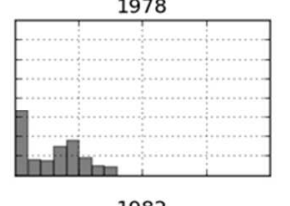

1982

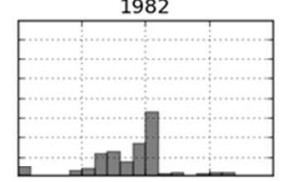

1986

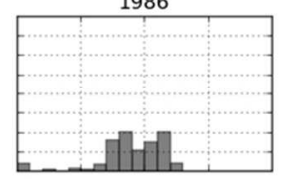

1990

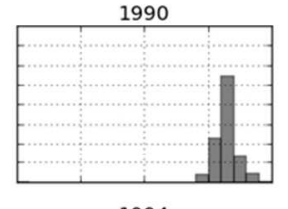

1994

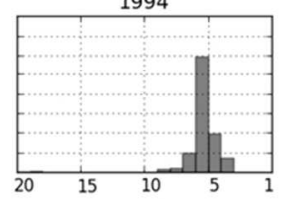

1979

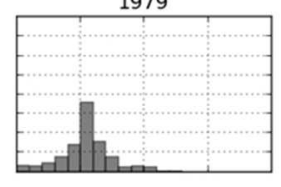

1983

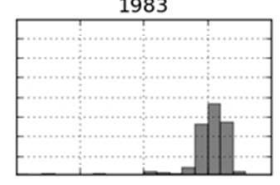

1987

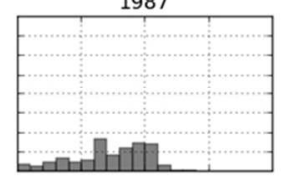

1991

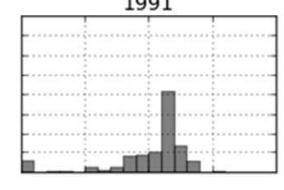

1995

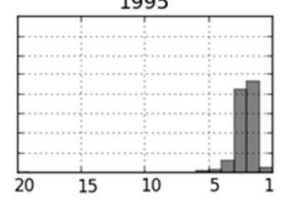

Figure 5 C10 - Ranking probability by the number of hours over BS EN 15251 adaptive Category I for Living rooms

$82 \times 65 \mathrm{~mm}(300 \times 300$ DPI $)$ 

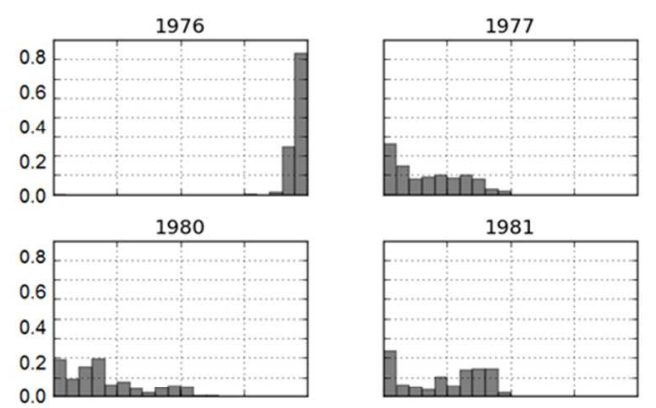

1981
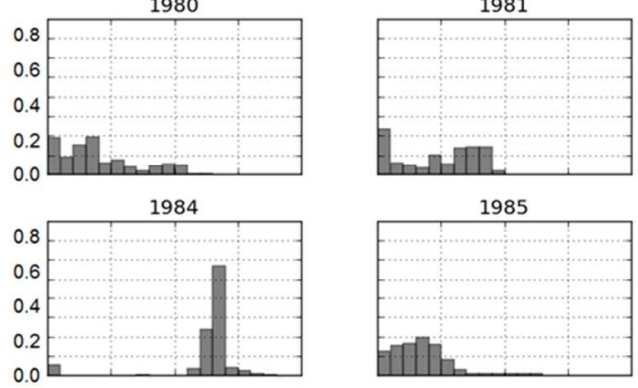

1988

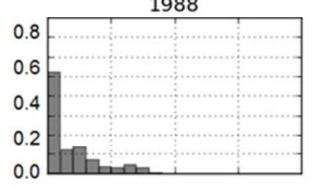

1992

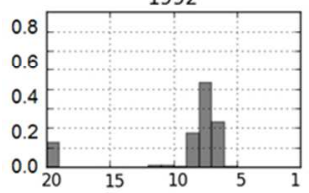

1985

1989

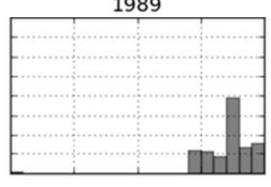

1993

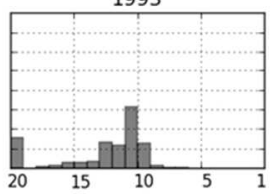

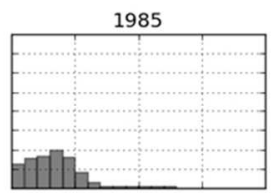

1978

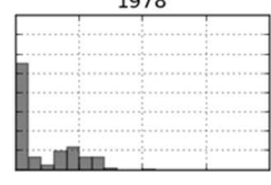

1982

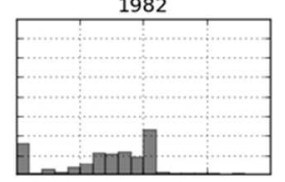

1986

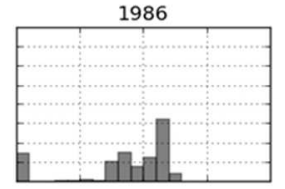

1990

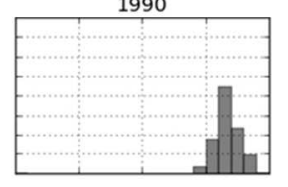

1994

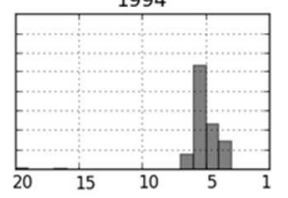

1979

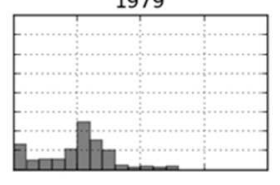

1983

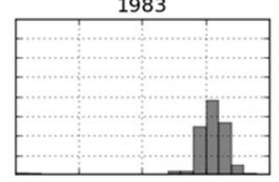

1987

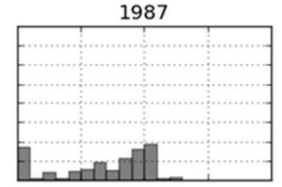

1991

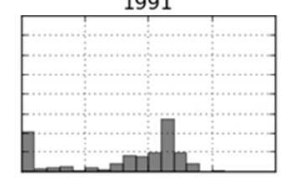

1995

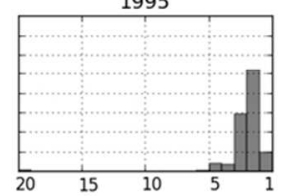

Figure 6 C12 - Ranking probability by the number of hours over BS EN 15251 adaptive Category II for Living rooms $83 \times 65 \mathrm{~mm}(300 \times 300$ DPI $)$ 

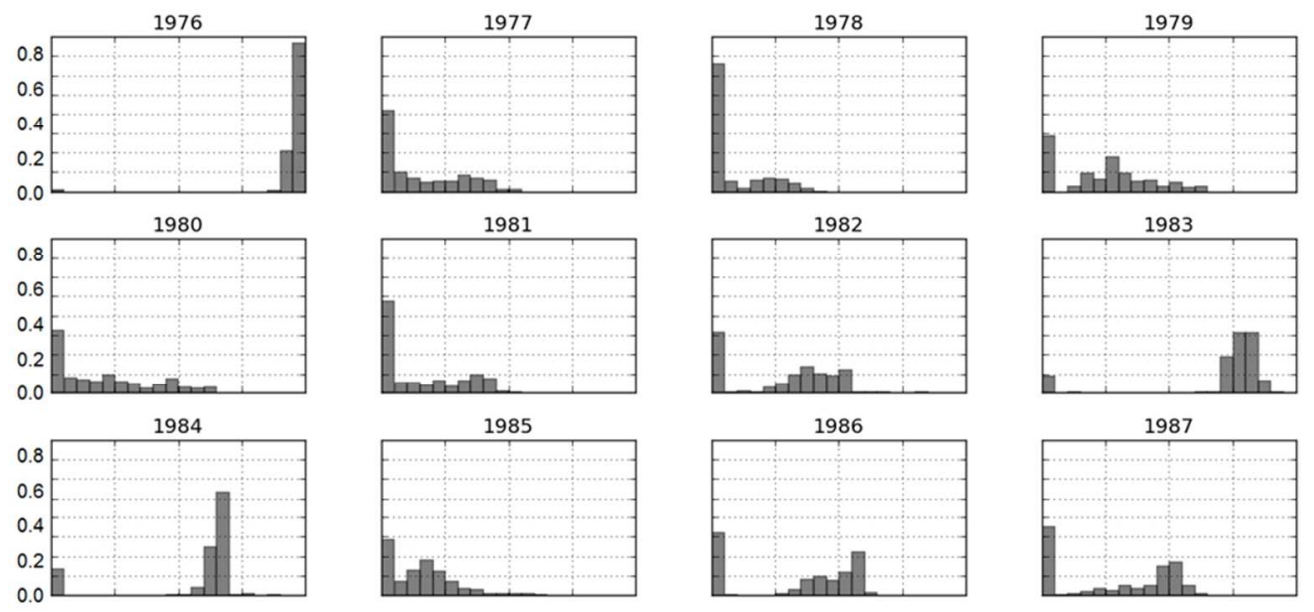

1985

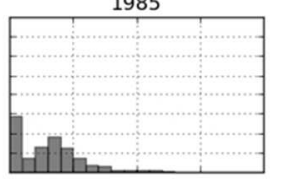

1986
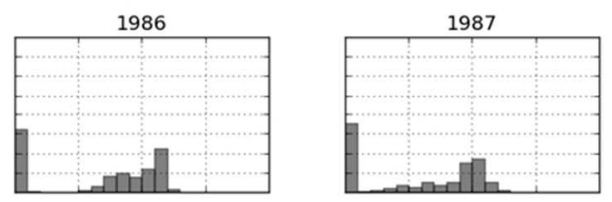

1989
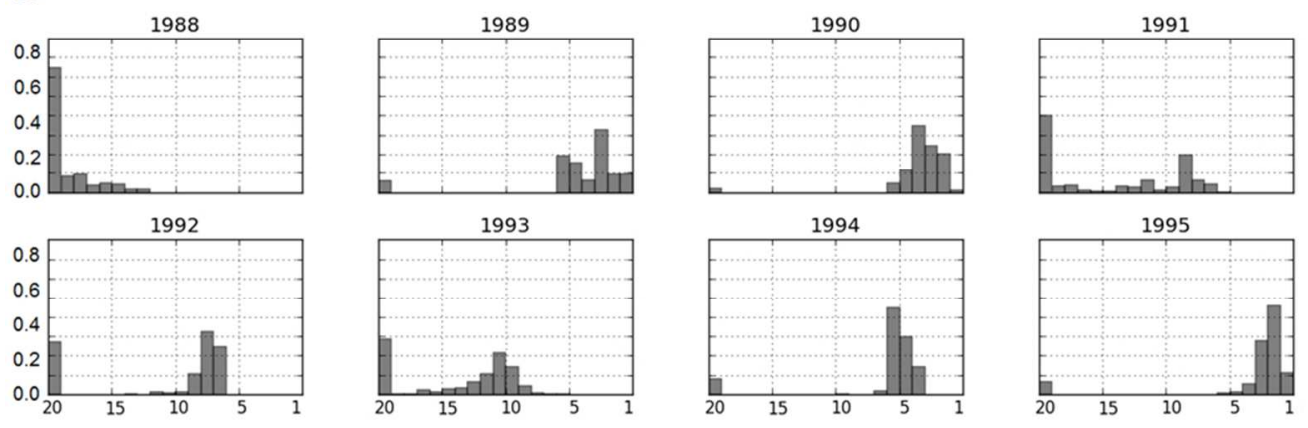

Figure 7 C14 - Ranking probability by the number of hours over BS EN 15251 adaptive Category III for Living rooms $83 \times 66 \mathrm{~mm}(300 \times 300 \mathrm{DPI})$ 


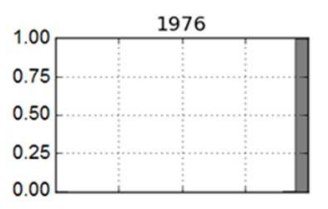

1980

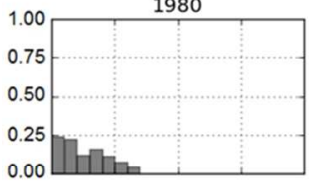

1984

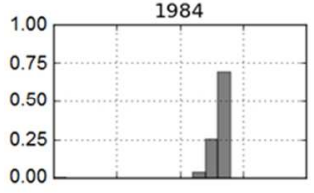

1988

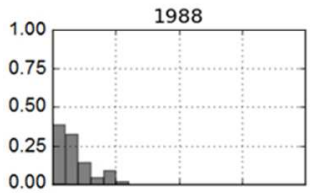

1992

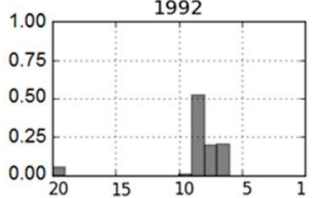

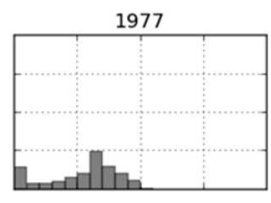

1981

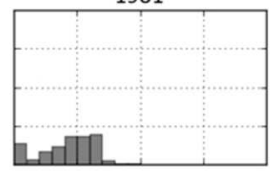

1985

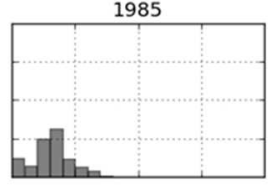

1989

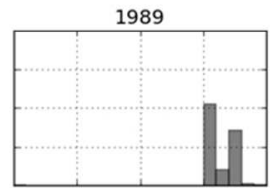

1993

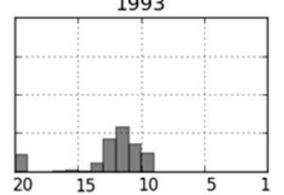

1978

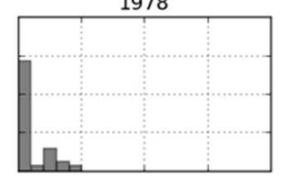

1982

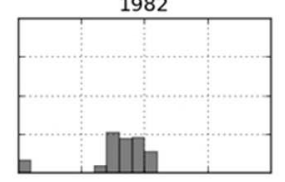

1986

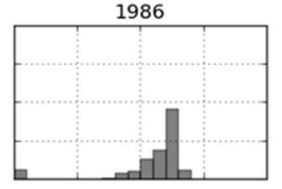

1990

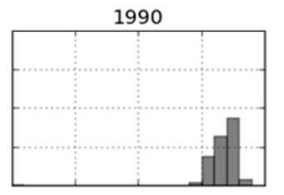

1994

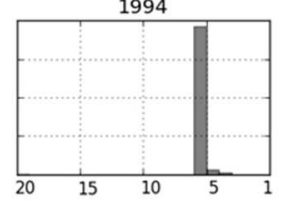

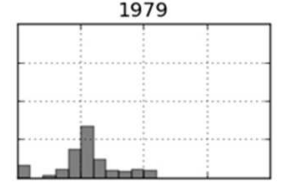

1983

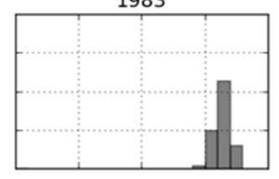

1987

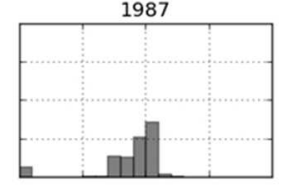

1991

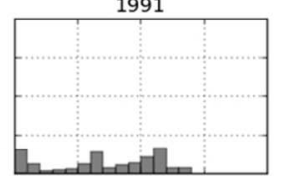

1995

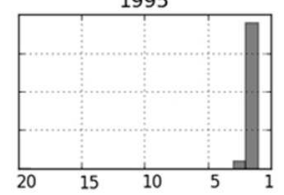

Figure 8 C3 - Ranking probability by the number of accumulated degree hours over 28C for Living rooms $83 \times 65 \mathrm{~mm}(300 \times 300$ DPI $)$ 
Figure 9 C11- Ranking probability by the number of accumulated degree hours over adaptive Category I for Living Rooms

$83 \times 65 \mathrm{~mm}(300 \times 300$ DPI $)$ 


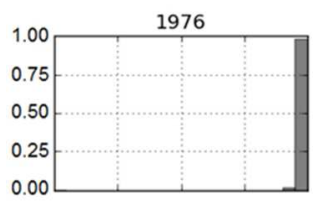

1980

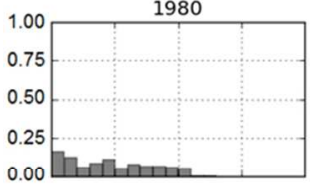

1984

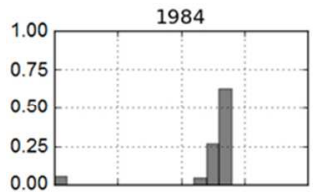

1988

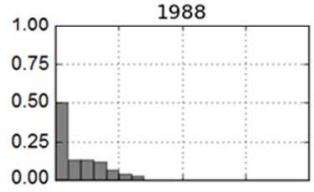

1992

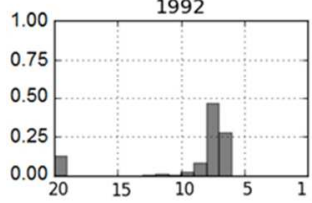

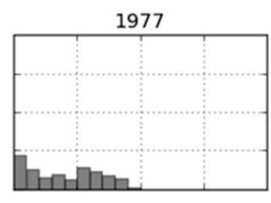

1981

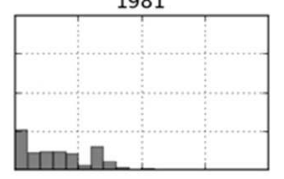

1985

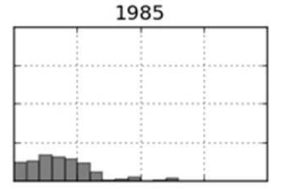

1989

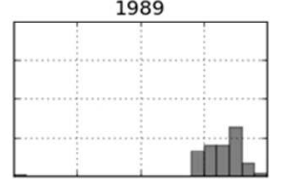

1993

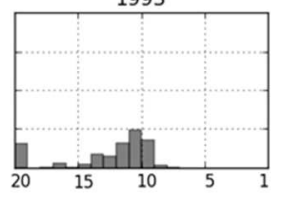

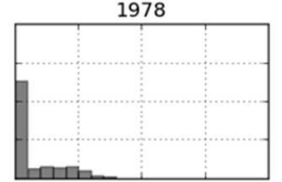

1982

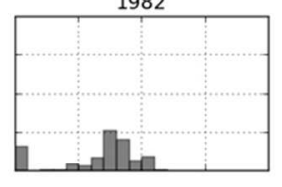

1986

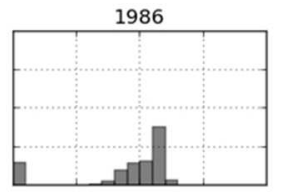

1990

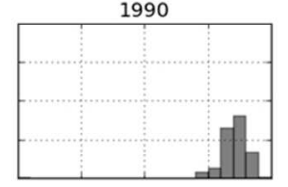

1994

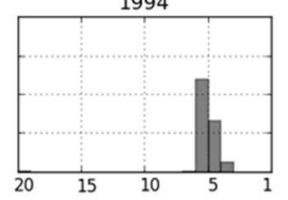

1979

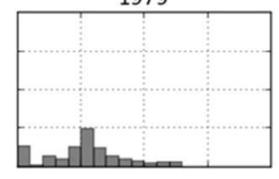

1983

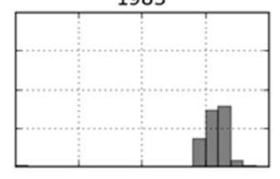

1987

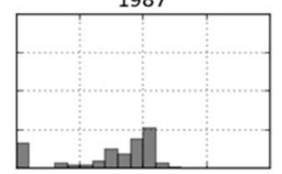

1991

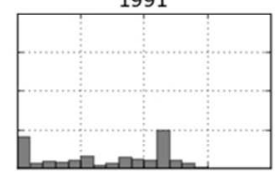

1995

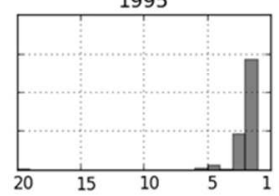

Figure 10 C13 - Ranking probability by the number of accumulated degree hours over adaptive Category II for Living Rooms $83 \times 65 \mathrm{~mm}(300 \times 300$ DPI $)$ 

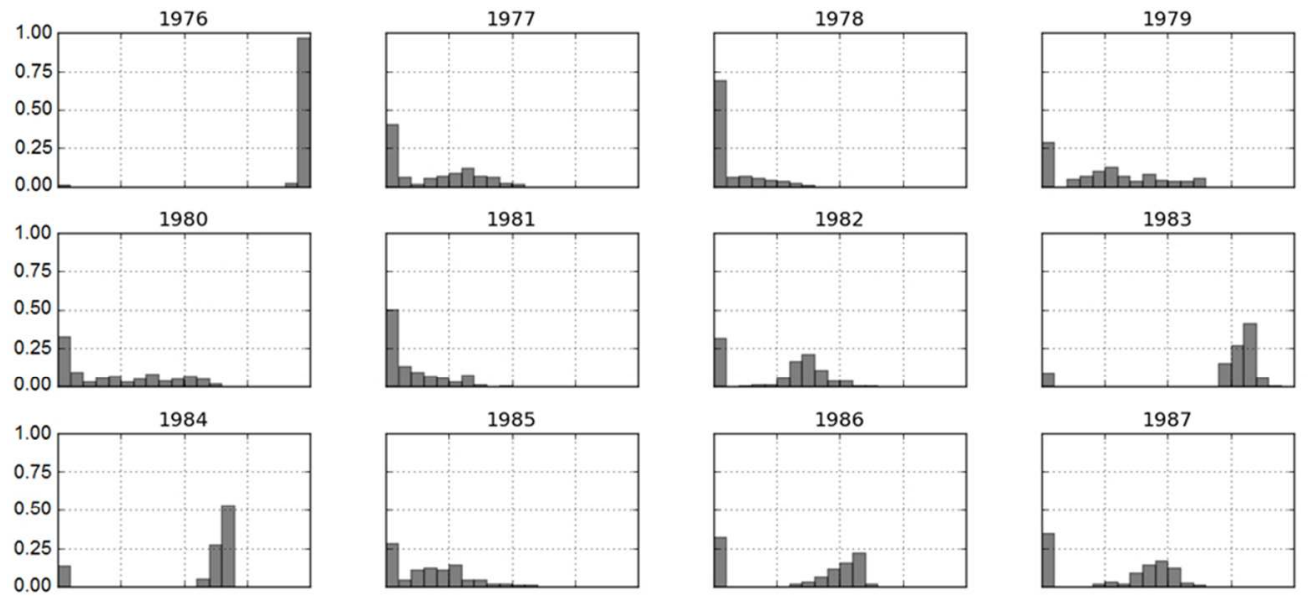

1985

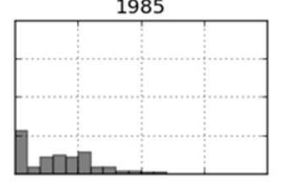

1986

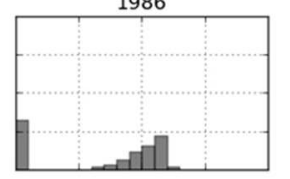

1987

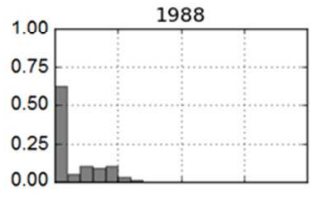

1989

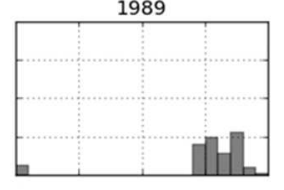

1990

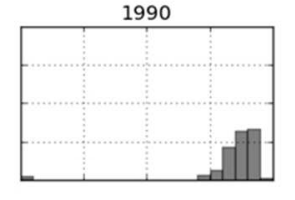

1994
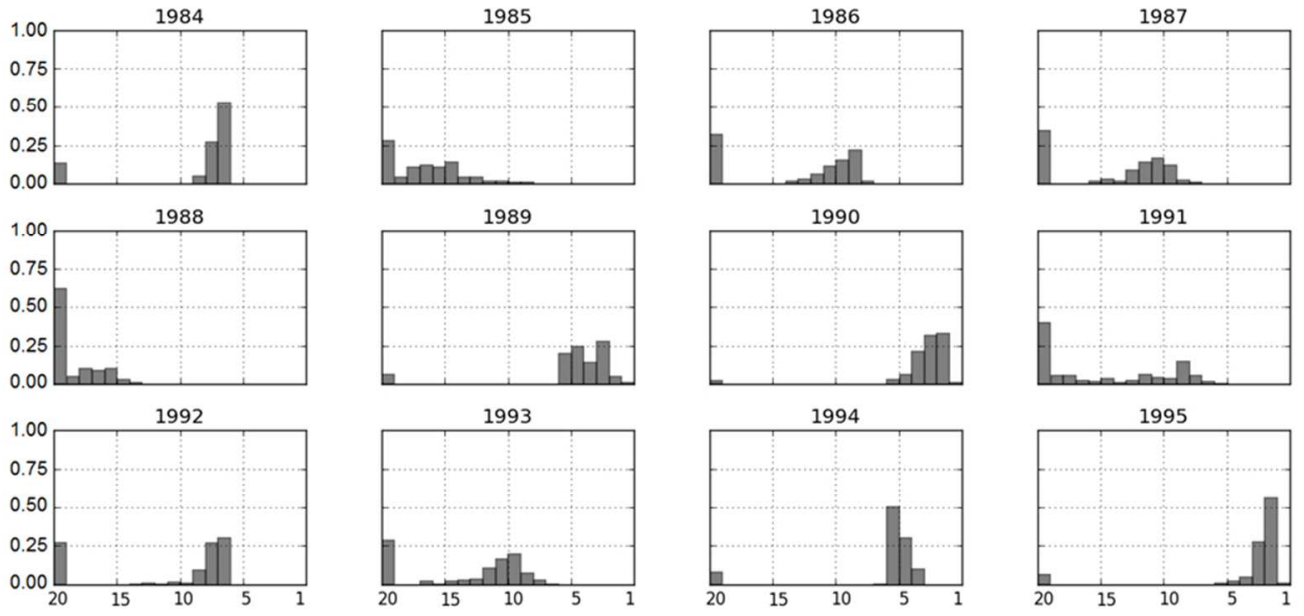

1991

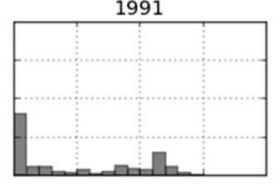

1995

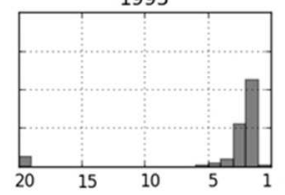

Figure 11 C15 - Ranking probability by the number of accumulated degree hours over adaptive Category III for Living Rooms $83 \times 66 \mathrm{~mm}(300 \times 300$ DPI $)$ 